\title{
Postnatal Disruption of the Disintegrin/Metalloproteinase ADAM10 in Brain Causes Epileptic Seizures, Learning Deficits, Altered Spine Morphology, and Defective Synaptic Functions
}

\author{
Johannes Prox, ${ }^{1}$ Christian Bernreuther, ${ }^{2}$ Hermann Altmeppen, ${ }^{2}$ Jasper Grendel, ${ }^{3}$ Markus Glatzel, ${ }^{2}$ Rudi D’Hooge, ${ }^{4}$ \\ Stijn Stroobants, ${ }^{4}$ Tariq Ahmed, ${ }^{4}$ Detlef Balschun, ${ }^{4}$ Michael Willem, ${ }^{5}$ Sven Lammich, ${ }^{5}$ Dirk Isbrandt, ${ }^{3}$ \\ Michaela Schweizer, ${ }^{3}$ Katrien Horré, ${ }^{6,7}$ Bart De Strooper, ${ }^{6,7}$ and Paul Saftig ${ }^{1}$ \\ ${ }^{1}$ Institut für Biochemie, Christian-Albrechts-Universität zu Kiel, D-24098 Kiel, Germany, ${ }^{2}$ Institute of Neuropathology and ${ }^{3}$ Center for Molecular \\ Neurobiology, University Medical Center Hamburg-Eppendorf, D-20246 Hamburg, Germany, ${ }^{4}$ Laboratory of Biological Psychology, University of Leuven, \\ B-3000 Leuven, Belgium, ${ }^{5}$ Adolf-Butenandt-Institute, Biochemistry, Ludwig-Maximilians-University, 80336 Munich, Germany, ${ }^{6}$ VIB Center for the Biology \\ of Disease, 3000 Leuven, Belgium, and ${ }^{7}$ Center for Human Genetics, Universitaire Ziekenhuizen Leuven, University of Leuven, 3000 Leuven, Belgium
}

The metalloproteinase ADAM10 is of importance for Notch-dependent cortical brain development. The protease is tightly linked with $\alpha$-secretase activity toward the amyloid precursor protein (APP) substrate. Increasing ADAM10 activity is suggested as a therapy to prevent the production of the neurotoxic amyloid $\beta(\mathrm{A} \beta)$ peptide in Alzheimer's disease. To investigate the function of ADAM10 in postnatal brain, we generated Adam 10 conditional knock-out (A10cKO) mice using a CaMKII $\alpha$-Cre deleter strain. The lack of ADAM10 protein expression was evident in the brain cortex leading to a reduced generation of sAPP $\alpha$ and increased levels of sAPP $\beta$ and endogenous $\mathrm{A} \beta$ peptides. The $\mathrm{A} 10 \mathrm{cKO}$ mice are characterized by weight loss and increased mortality after weaning associated with seizures. Behavioral comparison of adult mice revealed that the loss of ADAM10 in the A10cK0 mice resulted in decreased neuromotor abilities and reduced learning performance, which were associated with altered in vivo network activities in the hippocampal CA1 region and impaired synaptic function. Histological and ultrastructural analysis of ADAM10-depleted brain revealed astrogliosis, microglia activation, and impaired number and altered morphology of postsynaptic spine structures. A defect in spine morphology was further supported by a reduction of the expression of NMDA receptors subunit $2 \mathrm{~A}$ and $2 \mathrm{~B}$. The reduced shedding of essential postsynaptic cell adhesion proteins such as N-Cadherin, Nectin-1, and APP may explain the postsynaptic defects and the impaired learning, altered network activity, and synaptic plasticity of the A10cKO mice. Our study reveals that ADAM10 is instrumental for synaptic and neuronal network function in the adult murine brain.

\section{Introduction}

ADAM10 is a central protease involved in ectodomain shedding and regulated intramembrane proteolysis (Reiss and Saftig, 2009; Weber and Saftig, 2012). The best known in vivo substrates of

Received Dec. 21, 2012; revised May 6, 2013; accepted June 6, 2013.

Author contributions: J.P., C.B., M.G., R.D., M.W., S.L., D.I.,M.S., B.D.S., and P.S. designed research;J.P., C.B., H.A., J.G., S.S., T.A., D.B., M.W.,S.L., D.I., M.S., and K.H. performed research; J.P., C.B., H.A., J.G., M.G., R.D., S.S., T.A., M.W., S.L., D.I., M.S., B.D.S., and P.S. analyzed data; J.P., R.D., S.S., T.A., M.W., S.L., D.I., M.S., B.D.S., and P.S. wrote the paper.

This work was supported by the Deutsche Forschungsgemeinschaft (DFG) SFB 877 and SFB 596 (A9); Interuniversity Attraction Poles Program IUAP P7/16 of the Belgian Federal Science Policy Office; the Fund for Scientific Research, Flanders; the K.U. Leuven (GOA12/008); the VIB; and a Methusalem Grant from the K.U. Leuven and the Flemish government. H.A. is supported by the Werner Otto Stiftung, M.G. is supported by the DFG Forschergruppe 885, and D.I. is supported by the DFG (IS63/3-1,2 and SFB936 B3). We are also thankful to Heike Hampel, Melanie Neumann (UKE, Mousepathology Core-Facility), Leen Van Aerschot, and Marlies Rusch for their assistance in this project.

Correspondence should be addressed to Paul Saftig, Institut für Biochemie, Christian-Albrechts-Universität zu Kiel, Olshausenstrasse 40, D-24098 Kiel, Germany. E-mail: psaftig@biochem.uni-kiel.de.

DOI:10.1523/JNEUROSCI.5910-12.2013

Copyright $\odot 2013$ the authors $\quad 0270-6474 / 13 / 3312915-14 \$ 15.00 / 0$
ADAM10 are the amyloid precursor protein (APP) and the Notch1 receptor. In Alzheimer's disease (AD) the ADAM10mediated $\alpha$-secretase activity toward APP is a mechanism to prevent the excessive production of the neurotoxic amyloid $\beta(\mathrm{A} \beta)$ peptide (Postina et al., 2004). The processing of APP by ADAM10 occurs within the peptide sequence of $A \beta$. This cleavage also generates a soluble N-terminal APP fragment $(\operatorname{sAPP} \alpha)$ with apparent neurotrophic and neuroprotective functions (Chasseigneaux and Allinquant, 2012). Enhancement of ADAM10 expression was suggested as a suitable therapeutic approach for the treatment of $\mathrm{AD}$ (Endres and Fahrenholz, 2010). Currently clinical trials are performed that address the question if induction of ADAM10 expression by aromatic retinoic acid derivatives is beneficial. Modulation of ADAM10 activity should, however, be regarded with care since apart from Notch1 and APP more than 20 additional substrates of ADAM10 have been identified to date (Weber and Saftig, 2012). In the brain, next to APP (Lammich et al., 1999; Jorissen et al., 2010; Kuhn et al., 2010) ADAM10 has been implicated in the shedding of ephrins (Hattori et al., 2000; 
Janes et al., 2005), cellular prion protein (Vincent et al., 2001; Altmeppen et al., 2011), neuronal adhesion molecule (Hinkle et al., 2006), L1 adhesion molecule (Gutwein et al., 2003), RAGE (Raucci et al., 2008), Nectin-1 (Kim et al., 2010), $\gamma$-ProtoCadherin C3 (Reiss et al., 2006), N-Cadherin (Reiss et al., 2005), and neuroligin-1 (Suzuki et al., 2012). Despite this multitude of ADAM10 substrates the embryonic lethal phenotype of classical ADAM10 knock-out mice (Hartmann et al., 2002) as well as the observations in conditional knock-out mice in the developing CNS using a Nestin-Cre-mediated disruption of the protease (Jorissen et al., 2010) are mainly explained by a disruption of the Notch1 signaling pathway. Embryonic CNS deletion of ADAM10 in neural progenitor cells led to perinatal lethality due to a disrupted neocortex and precocious neuronal differentiation of neuroepithelial and radial glial cells. Notch1-regulated target genes were severely downregulated in $\mathrm{A} 10 \mathrm{cKO}$ brains and this could be explained by a largely abolished S2 cleavage of Notch1 and a lack of the signal competent intracellular domain of Notch1 (Jorissen et al., 2010). In the past, the function of ADAM10 in adult brain could only be deduced by indirect means. Applying the tissue inhibitor of metalloproteinase-1 (TIMP-1) or a cellpermeable ADAM10 peptide, which interferes with its binding to the synapse-associated protein 97 , led to inhibition of the transport of ADAM10 to the postsynaptic surface thereby locally reducing its activity. As a consequence an increased size of dendritic spines, a modification of the synaptic AMPA receptors, and an increase of $\mathrm{A} \beta$ aggregate formation were observed (Marcello et al., 2007; Epis et al., 2010). It could be shown that these alterations may be tightly linked with an apparent lack of $\mathrm{N}$-Cadherin shedding at the postsynaptic membrane (Malinverno et al., 2010).

We decided to specifically disrupt ADAM10 in the postnatal brain using Adam10 floxed mice crossed with CaMKII $\alpha$-Cre transgenic mice. Although the lack of ADAM10 in central brain regions did not cause major morphological changes, synaptic dysfunction led to epileptic seizures, altered behavior, and an increased early perinatal lethality around weaning of the $\mathrm{A} 10 \mathrm{cKO}$ mice.

\section{Materials and Methods}

Generation of Adam10 cKO mice. Genotypes of the floxed mice were determined by PCR (Jorissen et al., 2010). To generate Adam10 cKO mice, homozygous floxed mice $\left(\operatorname{Adam} 10^{\mathrm{F} / \mathrm{F}}\right)$ were crossed with CaMKII $\alpha$-Cre transgenic mice (Casanova et al., 2001) to obtain mice heterozygous for the floxed Adam10 allele and hemizygous for the CaMKII $\alpha$-Cre allele (Genotyping Primer: 5'ATGCGCTGGGCTCTATGGCTTCTG3'， 5'TGCACACCTCCCTCTGCATGCACG3'), which were then crossed with $A$ dam $10^{\mathrm{F} / \mathrm{F}}$ mice to obtain Adam $10 \mathrm{cKO}$ mice. Crenegative $\operatorname{Adam} 10^{\mathrm{F} / \mathrm{F}}$ or Adam $10^{\mathrm{F} /+}$ were used as controls.

Western blot analysis of brain samples. Brain regions (cortex, hippocampus, midbrain and cerebellum) were taken from animals (age: postnatal day 5 (P5), P10, P17, and P20) and were lysed using cell lysis buffer (5 mm Tris base, 1 mм EGTA, 250 mm sucrose, 1\% Triton X-100). Postnuclear fractions were taken, proteins were quantified using standard BCA assay (Pierce), and 20-50 $\mu \mathrm{g}$ of protein/lane was loaded on $10 \%$ SDS-PAGE gels or $4-12 \%$ gradient BIS/Tris NuPAGE gels (Invitrogen) and transferred to nitrocellulose membranes (Roth) to perform Western blot analysis. Primary antibodies were as follows: anti-ADAM10 (polyclonal antiserum, B42.1), anti-glial fibrillary acidic protein (GFAP; G3893; Sigma-Aldrich), anti-Actin (A2066; Sigma-Aldrich), anti-NCadherin (\#610920; BD Transduction Laboratories), and antiNectin-1 (Kim et al., 2010; Lim et al., 2012). Analysis of APP processing was performed using cortical, cerebellar, and midbrain lysates of $\mathrm{A} 10 \mathrm{cKO}$ and control brains. Selected brain regions were lysed using DEA extraction buffer $(50 \mathrm{~mm} \mathrm{NaCl}, 0.2 \%$ diethylamine, $\mathrm{pH} 10$, plus protease
inhibitors;Sigma P8340) and lysates were centrifuged $(5000 \times g, 10 \mathrm{~min}$, $4^{\circ} \mathrm{C}$ ) to pellet cell fragments, which were lysed in $1 \mathrm{ml}$ of radioimmunoprecipitation assay (RIPA) buffer $\left(20 \mathrm{~min}\right.$, on a shaker at $\left.4^{\circ} \mathrm{C}\right)$. Both fractions were ultracentrifuged $\left(30 \mathrm{~min}, 100000 \times \mathrm{g}, 4^{\circ} \mathrm{C}\right)$ to collect DEA fractions and RIPA fractions. For $\mathrm{pH}$ adjustment $10 \% 0.5 \mathrm{~m}$ Tris, $\mathrm{pH} 6.8$ was added to the DEA fractions. To determine protein concentration in RIPA lysates, Pierce BCA protein assay (Thermo Scientific) was used. Eight percent Tris-glycine SDS polyacrylamide gels were used to separate $30 \mu \mathrm{g}$ of total protein per sample.

For size determination, SeeBlue Plus 2 Prestained Standard marker (Invitrogen) was used. Proteins were transferred to PVDF membranes for $75 \mathrm{~min}$ at a maximum of $400 \mathrm{~mA}$ using Tris-glycine blotting buffer without detergent. Membranes were blocked with I-Block-PBS (Invitrogen, T2015) for at least $45 \mathrm{~min}$ and subsequently exposed to primary antibody (15-20 ml) overnight at $4^{\circ} \mathrm{C}$ in I-Block-PBS. The next day, membranes were washed in Tris-buffered saline/Tween 20 (TBST) three times for at least $10 \mathrm{~min}$ at room temperature, then incubated with $10 \mathrm{ml}$ of TBST and horseradish peroxidase (HRP)-coupled secondary antibody (Promega) for $1 \mathrm{~h}$ at room temperature and washed again as before. For detection, ECL reagents (GE Healthcare) were used, and chemiluminescence was exposed to $\mathrm{x}$-ray imaging films developed with Cawomat 2000 IR (CAWO). The following antibodies were used: APP 22C11 (APP N terminus; Merck-Millipore; 1:2000), APP (APP C terminus; SigmaAldrich A8717; 1:2000), sAPP $\alpha$ (A $\beta /$ sAPP- $\alpha$; Signet SIG-39153; 1:1000), APP 192wt (sAPP- $\beta$ (SEVKM); kind gift from Elan; $1 \mu \mathrm{g} / \mathrm{ml})$, PSD-95 6G6-1C9 (PSD-95; Merck-Millipore MAB1596; 1:500), N-Cadherin (NCadh. AA802-819, BD Biosciences; 1:2000), NMDAR2A (GluN2A; 4205S; 1:1000; Cell Signaling Technology), NMDAR2B (GluN2B N terminus; N59/36; 1:100; NeuroMab), Calnexin AF18 (Calnexin C terminus; ADI-SPA-860F; 1:5000; Enzo), and $\beta$-Actin AC74 ( $\beta$-Actin N terminus; A5316; 1:5000; Sigma-Aldrich).

$A \beta$ ELISA screen. Snap frozen brain samples were homogenized in $0.4 \% \mathrm{DEA} / \mathrm{NaCl}$. After ultracentrifugation for $30 \mathrm{~min}$ at $4{ }^{\circ} \mathrm{C} 10 \%$ of $0.5 \mathrm{M}$ Tris- $\mathrm{HCl}, \mathrm{pH} 6.8$, is added to the supernatant and the resulting sample was used for the ELISA determinations. The 96-well plates were coated with the capture antibodies specific for $\mathrm{A} \beta 40$ or $\mathrm{A} \beta 42$. After overnight coating, plates were washed with $1 \times \mathrm{PBS} / 0.05 \%$ Tween 20 and blocked for $4 \mathrm{~h}$ at room temperature with $0,1 \%$ casein and after that washed again. $\mathrm{A} \beta$ standards (from rPeptide) and samples were loaded on the plates in the presence of a rodent-specific HRP-labeled detection antibody and incubated overnight at $4^{\circ} \mathrm{C}$. Next day, plates were washed with $1 \times$ PBS/0.05\% Tween 20 and developed using TMB substrate. Coating and detection antibodies are provided by M. Mercken (Johnson \& Johnson Pharmaceuticals Research and Development) (Zhou et al., 2011).

Sample preparation and immunohistochemical analysis. After perfusion brain tissue was fixed by immersion in $4 \%$ buffered formalin. After overnight postfixation, brains were dehydrated in ascending ethanol concentrations and embedded in low melting point paraffin following standard laboratory procedures. From all paraffin blocks, $4 \mu \mathrm{m}$ sections were stained with hematoxylin and eosin (H\&E) following standard laboratory procedures and were submitted to immunostaining following standard immunohistochemistry procedures using the Ventana Benchmark XT machine (Ventana). Briefly, deparaffinated sections were boiled for $30-60 \mathrm{~min}$ in $10 \mathrm{~mm}$ citrate buffer, $\mathrm{pH} 6.0$, for antigen retrieval. All solutions provided by Ventana. Sections were then incubated with primary antibody in 5\% goat serum (Dianova), $45 \%$ Tris-buffered saline, $\mathrm{pH} 7.6$, and $0.1 \%$ Triton X-100 in antibody diluent solution (Zytomed) for $1 \mathrm{~h}$ followed by detection with anti-rabbit or anti-goat histofine Simple Stain MAX PO Universal immunoperoxidase polymer or Mouse Stain Kit (for detection of mouse antibodies on mouse sections). For immunohistochemical double staining with antibodies against Ki67 and GFAP antibody antigen retrieval was performed with the Ventana Benchmark XT machine as described above followed by incubation with anti-Ki67 antibody and detection with anti-rabbit histofine Simple Stain MAX PO Universal immunoperoxidase polymer. Then, antibodies were denatured for $12 \mathrm{~min}$ at $95^{\circ} \mathrm{C}$ followed by incubation with anti-GFAP antibodies and detection with anti-mouse and anti-rabbit histofine Simple Stain MAX AP Universal immunoperoxidase polymer. All secondary antibody polymers were purchased from Nichirei Biosciences. Detection 
of antibodies was performed with "Ultra View Universal DAB Detection Kit" or "Ultra View Universal Alkaline Phosphatase Red Detection Kit" from Ventana according to standard settings of the machine. The counterstaining was also performed by the machine. Vasculature and connective tissue served as internal negative controls; additional negative controls included sections treated with secondary antibody only. The following primary antibodies were used: monoclonal anti-NeuN (1:50; MAB377B, Millipore), anti-GFAP (1:200; M0761, Dako Cytomation), anti-NMDAR (NR, Ab28669; Abcam), anti-Iba-1 (1:500; 019-19741, Wako Chemicals), and anti-Ki67 (1:100; ab15580, Abcam). Golgi staining was performed according to manufacturers protocol (FD Rapid GolgiStain Kit; FD NeuroTechnologies).

Ultrastructural analysis of hippocampal sections. Mice were perfused with $4 \%$ paraformaldehyde and $1 \%$ glutaraldehyde in PBS, $\mathrm{pH} 7.4$. Vibratome sections ( $60 \mu \mathrm{m}$ thick) of the hippocampal region were cut and postfixed in $1 \% \mathrm{OsO}_{4}$ and dehydrated and embedded in Epon. Semithin sections $(0.5 \mu \mathrm{m})$ were labeled with methylene blue. Ultrathin sections $(60 \mathrm{~nm})$ were stained with uranyl acetate and lead citrate and examined with a Zeiss EM 902. Hundreds of pictures from the stratum radiatum in the CA1 hippocampal region were randomly taken and asymmetric synapses and their postsynaptic structures from three Adam10 cKO and wt mice were examined.

Neuromotor tests. Cage activity was recorded in $20 \times 30 \mathrm{~cm}$ transparent cages, placed between 3 IR beams. The total number of beam crossings was recorded during $23 \mathrm{~h}$. Grip strength was measured using a T-shaped bar connected to a digital dynamometer (Ugo Basile). Mice were placed in such a way that they grabbed the bar spontaneously, and were softly pulled backward by the tail until they released their grip. Ten such readouts were recorded. Motor coordination and equilibrium were tested using an accelerating rotarod (Med Associates). Mice were first trained to maintain balance for $2 \mathrm{~min}$ at a constant speed of $4 \mathrm{rpm}$. This training trial was followed by four test trials, during which the rod accelerated from 4 to $40 \mathrm{rpm}$ in $5 \mathrm{~min}$. Consecutive trials were separated by a $10 \mathrm{~min}$ intertrial interval. Latency to falling off the rod was recorded up to $5 \mathrm{~min}$.

Exploratory tests. Open field exploration was tested in a brightly illuminated $50 \times 50 \mathrm{~cm}$ square arena subsequent to $30 \mathrm{~min}$ of dark adaptation. Movements in the arena were video-tracked for $10 \mathrm{~min}$ (EthoVision; Noldus $\mathrm{Bv}$ ). Total path length, percentage of path length in the center (center $=30$ $\mathrm{cm}$ circle), rearing, time in the center, latency to center entry, and number of center and corner entries were assessed. In the social exploration test, the same procedure was applied as in open field, except that a round wire cage with two female mice was placed in the center of the arena. Anxiety-related exploration was measured in an elevated plus maze, which mice could freely explore for $10 \mathrm{~min}$. The arena consisted of a plus-shaped maze with two arms $(5 \mathrm{~cm}$ wide) closed by side walls and two arms without walls. Four IR beams recording open and closed arm entries and one recording the percentage of time per minute spent in the open arms were connected to a computerized activity logger.

Learning and Memory. Passive avoidance learning was examined in a cage consisting of a light and a dark compartment containing a grid floor. After 30 min adaptation to the dark, the mouse was placed in the light compartment for a training trial. After $5 \mathrm{~s}$, the sliding door to the dark compartment was opened and step-through latency was manually recorded. When all four paws were placed on the grid floor, a mild electric shock $(0.3 \mathrm{~mA}, 1 \mathrm{~s})$ was delivered, using a constant current shocker (Med Associates). Retention was tested $24 \mathrm{~h}$ later, and latency to entrance was recorded up to a $300 \mathrm{~s}$ cutoff value. Visuospatial learning was assessed in a Morris-type water maze. The maze consisted of a circular pool (diameter: $150 \mathrm{~cm}$; height: $30 \mathrm{~cm}$ ) filled with opacified water and maintained at $26^{\circ} \mathrm{C}$. A round perspex platform $(15 \mathrm{~cm}$ diameter $)$ was placed inside the pool at the center of the target quadrant, $1 \mathrm{~cm}$ beneath water surface. One daily trial block consisted of four swimming trials randomly starting from one of the four different positions around the pool with $15 \mathrm{~min}$ intertrial intervals. If an animal could not find the platform within the maximum swimming time of $120 \mathrm{~s}$, it was placed on the platform, and had to stay there for $10 \mathrm{~s}$ before being allowed to return to its home cage. Acquisition of the task consisted of five trial blocks with a probe trial following these five blocks, during which mice had to swim for $100 \mathrm{~s}$ in the pool without a platform. The escape platform remained in the same position on all acquisition trial blocks. During the acquisition trials and the probe trial, the animals were tracked using EthoVision videotracking equipment and software (Noldus Bv). During the acquisition trials, escape latencies of the four daily trials were summed, and data were expressed as totals per daily trial blocks. During the probe trial, performance was expressed as percentage of time spent in the target quadrant and mean distance to the target.

Recording of hippocampal long-term potentiation. A group of seven female A10cKOs and six wild-type females were killed at 3 months of age for in vitro long-term potentiation (LTP) recordings. Hippocampal slices were prepared from these mice as described previously (Balschun et al., 2010) and immediately transferred to a submerged-type slice chamber, in which they were permanently perfused with $32^{\circ} \mathrm{C}$ artificial CSF (ACSF). After at least $1 \mathrm{~h}$ of incubation, a lacquer-coated stainless steel stimulating electrode and a glass recording electrode (filled with ACSF, $1-4 \mathrm{M}$ ) were placed into the stratum radiatum of the CA1 region to record field EPSPs (fEPSPs). The initial slope of the fEPSP served as a measure of this potential. Stimulation strength was adjusted to $35 \%$ of the maximum after constructing input/output curves and kept at this level throughout the experiment. During baseline recording, three single stimuli $(0.1 \mathrm{~ms}$ pulse width; $10 \mathrm{~s}$ interval) were measured every $5 \mathrm{~min}$. Once a stable baseline had been established, LTP was induced by a strong theta-burst stimulation (TBS, three trains of 10 burst of four stimuli at $100 \mathrm{~Hz}$, separated by $200 \mathrm{~ms}, 0.2 \mathrm{~ms}$ pulse width, applied every $10 \mathrm{~min}$; Larson and Lynch, 1986; Balschun et al., 2010). Evoked responses were recorded at 1,4 , and $7 \mathrm{~min}$ following each TBS, and then from $10 \mathrm{~min}$ after the third TBS every $5 \mathrm{~min}$ as during baseline recording. Potentiation was pursued for $2 \mathrm{~h}$. In all experiments, the recording of slices from mutant mice was interleaved by experiments with wild-type controls.

In vivo hippocampal recording and data analysis. Adult male mice were anesthetized with 1.1-1.4 mg/g b.w. urethane (10\% w/v; Sigma in $\mathrm{NaCl}$ $0.9 \%$ ), initial anesthesia during surgery was supplemented with $1.0-$ $1.5 \%$ isoflurane in $100 \%$ oxygen. Animals were placed in a stereotaxic apparatus (Stoelting). Body temperature was maintained at $36^{\circ} \mathrm{C}$ using a homeothermic heating pad (WPI). A midline skin incision was made on the top of the skull. For a common ground and reference electrode, a hole was drilled and a stainless steel screw connected to the ground wire was inserted above the cerebellum (lambda $-1.5 \mathrm{~mm}, 1.0 \mathrm{~mm}$ lateral). For the hippocampal silicon probe a $0.8 \mathrm{~mm}$ wide burr hole was placed at 2.0 $\mathrm{mm}$ posterior to bregma and $1.6 \mathrm{~mm}$ right to the midline. Isoflurane anesthesia was discontinued after surgery. During recording the mice remained head-fixed and body temperature was maintained at $36^{\circ} \mathrm{C}$ using a homeothermic heating pad (Stoelting). A linear 16-site silicon probe with a distance of $100 \mu \mathrm{m}$ between the recording sites $(\mathrm{a} 1 \mathrm{x}] 16-5$ mm-100-177; NeuroNexus Technologies) was inserted vertically into the dorsal hippocampus (2.1 $\mathrm{mm}$ deep) along the CA1-dentate gyrus axis and connected to a $1 \times$ preamplifier (Neuralynx) mounted to the stereotaxic instrument. Data were digitally filtered $(0.5-9000 \mathrm{~Hz}$ bandpass) and digitized as 16-bit integers with a sampling rate of $32 \mathrm{kHz}$ using a Digital Lynx 4SX data acquisition system (Neuralynx). Animal breathing rate was detected by a piezoelectric sensor placed under the animal's thorax and recorded in parallel with the same sampling rate. Data acquisition was started $\sim 15-30$ min after probe insertion when recording conditions were stable. Probe positions were marked by silicon probes covered by the fluorescence dye DiI and verified in NeuroTrace fluorescent Nissl-stained (Invitrogen) coronal slices, which were used in combination with the local field potential (LFP) depth profile for layer identification (Buzsáki et al., 2003).

All in vivo data were analyzed and visualized in MATLAB (MathWorks) or NeuroScope (Hazan et al., 2006). LFPs were downsampled to $1.25 \mathrm{kHz}$ from raw traces. Multitaper spectrograms were computed using Chronux (www.chronux.org; nFFT $=4096$ points, sliding window 2048 points). Paradoxical/REM-like epochs were manually selected and defined by the presence of theta $(4-8 \mathrm{~Hz})$ and gamma $(20-50 \mathrm{~Hz})$ oscillations. Theta and gamma power was calculated for the selected REM-like epochs by integrating the area below the theta and gamma ranges. Theta phase was calculated by the angle of the Hilbert transform on the theta band-filtered signal (Butterworth; third order, 4-8 Hz) whereas instantaneous gamma power was calculated by the absolute of the Hilbert 
Table 1. Progenies of crosses of Adam 10 ${ }^{\mathrm{F} / \mathrm{F}}$ with CaMKII $\alpha$-Cre: Adam10 ${ }^{\mathrm{F} /+}$

\begin{tabular}{llllll}
\hline & $F /+$ & & F/F & & ADAM10 \\
\hline Total $(n)$ & - & + & - & + & CaMKIla Cre \\
834 & 255 & 232 & 212 & 135 & \\
$\%$ of total & $30 \%$ & $25 \%$ & $27 \%$ & $16 \%$ & \\
\hline
\end{tabular}

transform on the gamma band-filtered signal (Butterworth; sixth order, $20-50 \mathrm{~Hz}$ ). Theta phase was binned in 20 degree blocks. The mean instantaneous gamma power within each theta phase block was calculated. Theta phase modulation of gamma power was then calculated using an adaptation of the Kullback-Leibler divergence (Tort et al., 2009).

For automatic ripple detection, the channel with the largest ripple amplitude was bandpass filtered (Butterworth; 14th order, 100-250 Hz). Ripples were defined as periods in which the instantaneous power exceeded four times the SD above the mean during slow-wave-sleep (SWS)-like brain states. The left and right borders of detected ripple events were defined as the time points where the instantaneous power dropped $<1.75$ SDs above the mean. Events shorter than 25 ms were excluded.

For each individual ripple, we calculated its amplitude and estimated its frequency. Ripple amplitude was obtained by measuring the average peak-to-peak amplitude on individual ripples on the bandpass-filtered signal. Ripple frequency was obtained by calculating the mean inverse distance between subsequent troughs. To obtain the ripple amplitude and frequency per animal, a mean was calculated for all detected ripples throughout a recording. Ripple occurrence was defined as the number of ripples per second of SWS-like brain states.

Statistical analysis. For body weight calculation and ELISA data evaluation, the statistical significance was calculated by Student's $t$ test using Microsoft Excel software. Error bars indicate the mean \pm SD of the mean; $p$ values: ${ }^{\star} p<0.05,{ }^{* *} p<0.01,{ }^{* *} p<0.001$.

Statistical significance in behavioral and electrophysiological testing was evaluated with SigmaStat software through ANOVA procedures, using repeated-measures designs where appropriate and the HolmSidak approach for post hoc comparisons of behavioral data. Statistical significance of behavioral differences is illustrated using the F-statistic with indication of degrees of freedom. One outlier was removed from water maze probe trial analysis (deflection of more than 2 SD from the mean). Intragroup differences in electrophysiological data were evaluated with the Wilcoxon matched-pairs signed rank test or Mann-Whitney test. Data are presented as the mean \pm SEM; $p$ values: ${ }^{\star} p<0.05$, ${ }^{* *} p<0.01,{ }^{* *} p<0.001$.

\section{Results}

\section{Generation of CaMKII $\alpha$-Cre-driven Adam10 conditional} knock-out mice

Our previous study of ADAM10 deletion in neuronal progenitor cells revealed an essential role of the protease in Notch1dependent cell-fate decisions and in prenatal neuronal development (Jorissen et al., 2010). However, the embryonic or perinatal lethality observed in these mice prompted us to study the consequences of ADAM10 deletion in postnatal neurons. Using CaMKII $\alpha$-Cre-deleter mice (Casanova et al., 2001) bred to ADAM $10^{\mathrm{F} / \mathrm{F}}$ mice we succeeded in obtaining viable offspring of all expected genotypes (Table 1). The number of conditional knock-outs (ADAM10 ${ }^{\mathrm{F} / \mathrm{F}} \mathrm{CaMKII} \alpha-\mathrm{Cre}$ ) was slightly less than expected suggesting some embryonal and undetected cases of death. This is also supported by our observation that a significant number of mice died between P18 and P27. However, we also obtained mice surviving for longer than 2 months especially when they received food at the bottom of the cage (Fig. 1A). In general, the conditional knock-outs featured a reduced size and weight (Fig. $1 B, C$ ) and a frequent development of seizures. Some A10cKO mice showed repetitive seizures starting from approximately P14. They began to tremble and move with their tiptoes presenting a stiff tail (Fig. 1D). In some cases severe tonic seizures were observed resulting in respiratory arrest and death. During acute in vivo depth recording under urethane anesthesia, we observed a hippocampal electrographic seizure in one of five mutants (Fig. 1E), while we never recorded such an event from control animals of this $(n=9)$ or other lines $(n>30)$. The surviving adult $\mathrm{A} 10 \mathrm{cKO}$ mice also displayed abnormal hindlimbclasping reflexes when lifted by their tail (Fig. $1 F$ ) indicating a more severe CNS impairment (Liou et al., 2003; Chen et al., 2005; Komatsu et al., 2006).

CaMKII $\alpha$-Cre expression was reported to start at approximately P5 (Casanova et al., 2001). We therefore analyzed cortical lysates obtained from control and A10cKOs for ADAM10 protein expression. A clear reduction of both proform and mature ADAM10 in the A10cKO samples was revealed, which was more pronounced at P17 as compared with P5 (Fig. 2A). Interestingly, in the same experiment we observed that in wild-type cortex samples postnatal ADAM10 expression increased with age whereas the appearance of the ADAM10 cytoplasmic fragment (CTF) was reduced, which is likely due to decreased activity of ADAM9 and ADAM15 (Tousseyn et al., 2009; Fig. 2A).

\section{APP $\alpha$-secretase processing is severely reduced in adult CNS from A10cKO mice}

To investigate ADAM10 deletion at a functional level and to address the open question if APP is an ADAM10 substrate also in adult neurons $\alpha$-secretase processing of the APP was analyzed. Whereas in cortex lysates the generation of the soluble APP $\alpha$-ectodomain fragment $(\mathrm{sAPP} \alpha)$ could be easily observed in control mice it was almost absent (5\% of control level) in A10cKO cortex lysates (Fig. 2B,C). No obvious differences in nontargeted brain regions, such as the cerebellum where the expression of APP was less pronounced, could be observed. The generation of the BACE-1-dependent soluble APP $\beta$ fragment (sAPP $\beta$ ) was $\sim 2$-fold increased in the A10cKO cortex samples suggesting that more uncleaved APP reaches the subcellular site with $\beta$-secretase activity (Fig. $2 B, C$ ). The increased $\beta$-secretase cleavage may also explain why only a minor increase in fulllength APP in A10cKO cortex lysates was observed. In cortex tissue of the A10cKO mice also the concentration of the ADAM10-dependent C-terminal membrane-bound APP fragments were clearly decreased (Fig. $2 D$ ). Importantly, determining the endogenous levels of the $A \beta$ species revealed a significant increase in both $\mathrm{A} \beta_{1-40}$ and $\mathrm{A} \beta_{1-42}$ in $\mathrm{A} 10 \mathrm{cKO}$ cortex but not in the nontargeted cerebellum samples, respectively (Fig. 2E).

We conclude that postnatal neuronal loss of ADAM10 expression in the A10cKO mice led to early and increased mortality, occurrence of epileptic seizures, and a significantly reduced $\alpha$-secretase-mediated APP processing.

\section{ADAM10 deletion in postnatal neurons leads to astrogliosis and microglial activation without affecting overall brain morphology}

The repeated early postnatal occurrence of seizures in the conditional knock-out mice prompted us to histologically study the CaMKII $\alpha$-Cre-targeted regions such as the hippocampus and the cortex at P20. H\&E staining did not reveal obvious abnormalities in the architecture and morphology of both brain regions (Fig. $3 A$ ) and staining with antibodies against the neuronal nuclear protein NeuN did not show differences between control and A10cKO brain sections (Fig. 3B). At this age already a prominent upregulation of the glia-specific protein GFAP with a pronounced astrogliosis in the hippocampus as well as in the cortical layers of the A10cKO mice was found (Fig. $3 \mathrm{Ca}-h$ ). Since double 
A

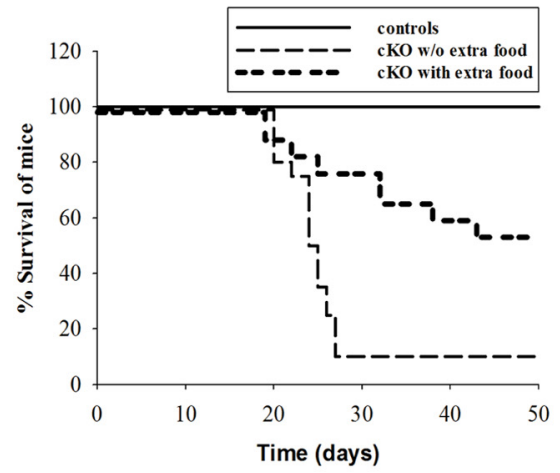

C

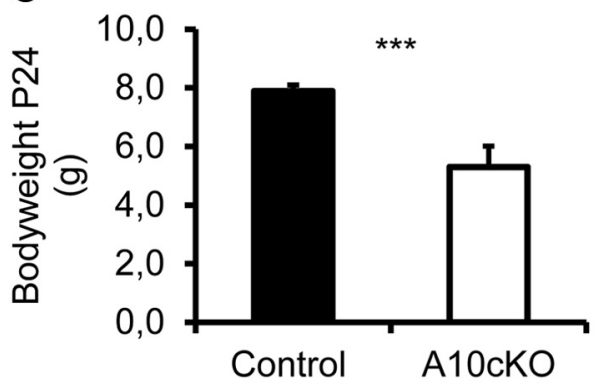

E

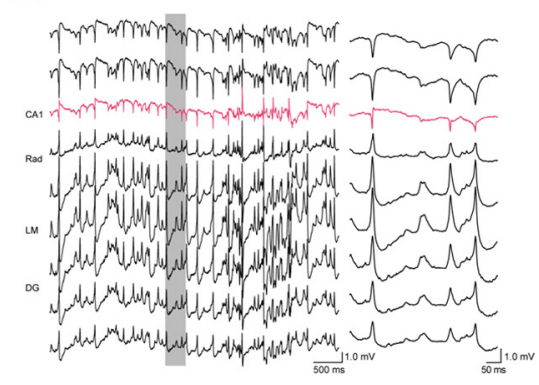

B

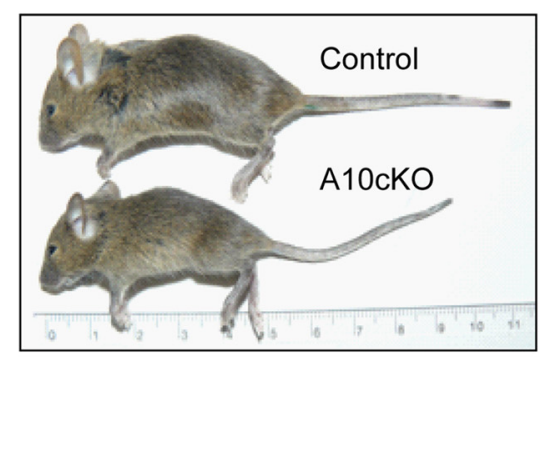

D

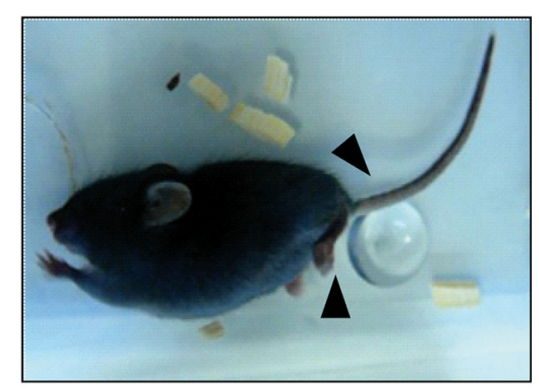

$\mathrm{F}$

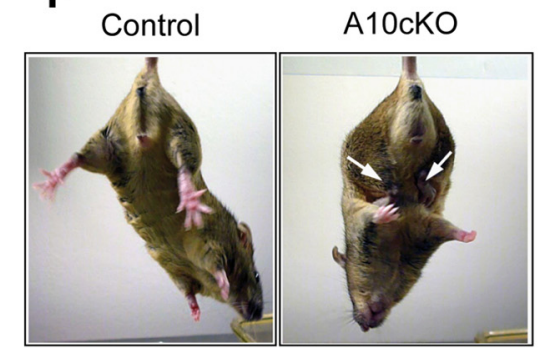

Figure 1. Basic characterization of A10cKOs with a postnatal neuronal ADAM10 deletion. $\boldsymbol{A}$, Kaplan-Meier analysis of survival of $A 10$ cKOs compared with controls according to the availability of extra food during the first $50 \mathrm{~d}$ of life. $\boldsymbol{B}$, Exemplary picture of the overall appearance of an A10cKO compared with a control mouse. C, Analysis of bodyweights of littermate controls and A10cKO mice $\left({ }^{* * *} p<0.001\right)$. D , Representative image (video snapshot) of an A10cK0 mouse during episodes of seizures. Black arrows indicate spastics of hindlegs and tail. $\boldsymbol{E}$, Silicon probe in vivo depth recording of electrographic seizure activity in the hippocampus of an A10cK0 mouse. The gray area on the left is shown in an expanded scale on the right. CA1, CA1 pyramidal layer; Rad, stratum radiatum; LM, stratum lacunosum moleculare. $\boldsymbol{F}$, Hindlimb clasping reflexes in 25-week-old control and A10cKO mice.

staining with Ki67 and GFAP did not reveal an increased proliferation of astrocytes the astrogliosis is likely due to astrocyte activation (Fig. 3Ci,j). The astrogliosis was also observed in 30week-old A10cKO mice and was accompanied by a robust microglial activation (Fig. 3D).

Postnatal neuronal depletion of ADAM10 is associated with impaired neuromotor function, altered exploration behavior, and reduced learning and memory

To better understand the role of ADAM10 in postnatal neurons we monitored various behavioral parameters in 2-month-old control and $\mathrm{A} 10 \mathrm{cKO}$ mice. Neuromotor tests showed that A10cKO mice did not differ from controls in circadian cage activity (Fig. $4 A$ ), but showed increased grip strength (Fig. $4 B$; $\left.F_{(1,11)}=4.9 ; p<0.05\right)$. The rotarod test revealed decreased motor performance in the mutant mice independent of trial (Fig. $4 C$; $\left.F_{(1,33)}=6.3 ; p<0.05\right)$.
A10cKOs generally tended to be more active in the elevated plus maze (Fig. $4 D$; $p=0.07)$. There were no differences between the groups in relative preferences for open versus closed arms (data not shown). In the open field test (Table 2), A10cKO mice spent less time in the center $\left(F_{(1,11)}=12.1 ; p<0.01\right)$ and traveled relatively less distance in the center $\left(F_{(1,11)}=\right.$ 12.7; $p<0.01)$. Similar tendencies of decreased center exploration came forward in the number of center entries and the latency to enter the center. Furthermore, A10cKOs showed reduced social exploration (Table 2) as indicated by significantly declined center entries $\left(F_{(1,11)}=\right.$ 5.6; $p<0.05)$, time spent in the center $\left(F_{(1,11)}=10.5: p<0.01\right)$, and percentage of path length in the center $\left(F_{(1,11)}=12.9\right.$; $p<0.01)$. Corner entries on the other hand were increased in $\mathrm{A} 10 \mathrm{cKO}$ mice $\left(F_{(1,11)}=5.4 ; p<0.05\right)$.

Passive avoidance learning was also impaired in A10cKOs as indicated by a significant Gen $\times$ Trial interaction (Fig. $\left.4 E ; F_{(1,10)}=17.9 ; p<0.001\right)$. They showed lower step through latencies, but only in the phase of testing. Likewise, A10cKO mice, in contrast to controls, did not learn the location of the escape platform in the acquisition phase of the water maze test (Fig. $4 F ; F_{(1,44)}=80 ; p<0.001$ ). However, A10cKO mice also showed significantly reduced swimming velocity (data not shown; $F_{(1,11)}=27 ; p<0.001$ ), which might have interfered with the learning task. The probe trial confirmed unsuccessful acquisition as $\mathrm{A} 10 \mathrm{cKO}$ mice spent less time in the target quadrant (Fig. $\left.4 G ; F_{(1,10)}=21 ; p<0.001\right)$ and swam further from the target on average (Fig. $\left.4 H ; F_{(1,10)}=27 ; p<0.001\right)$. In summary, the deletion of ADAM10 in postnatal neurons led to severe behavioral alterations and a significantly reduced ability in learning and memory.

\section{Normal hippocampal synaptic transmission but impaired LTP in A10cKO mice}

Basic synaptic transmission, short-term plasticity, and LTP were investigated through analysis of the Schaffer collateralcommissural pathway. As depicted in Figure 5A, A10cKO mice did not display significant differences in basic synaptic transmission, as evaluated by input-output curves. Paired-pulse ratio, a measure of short-term plasticity, yielded a difference at the 100 $\mathrm{ms}$ ratio ( $p=0.0299$ unpaired $t$ test with Welch's correction; Fig. $5 B)$. Next, we investigated whether deletion of ADAM10 had any functional impact on LTP, a prime candidate mechanism for memory formation at the cellular level. We used a type of LTP that is induced by strong TBS (three trains of 10 burst of four stimuli at $100 \mathrm{~Hz}$, separated by $200 \mathrm{~ms}, 0.2 \mathrm{~ms}$ pulse width; Larson and Lynch, 1986; Balschun et al., 2010). TBS mimics natural patterns of discharge of CA1 pyramidal cells as occurring in 
A

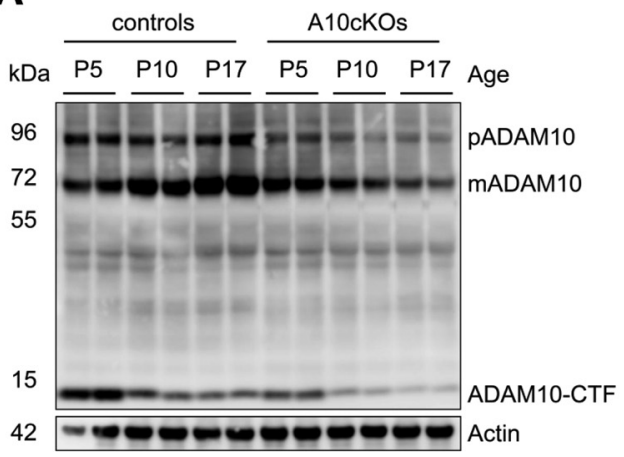

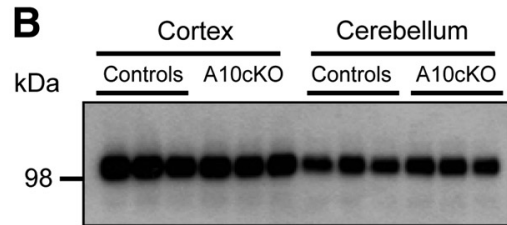

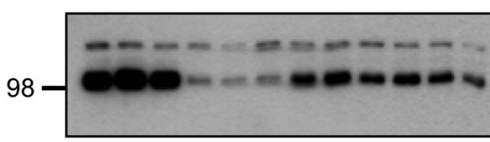

SAPP $\alpha$

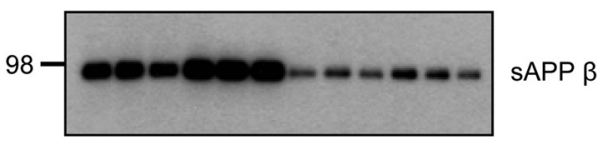

D

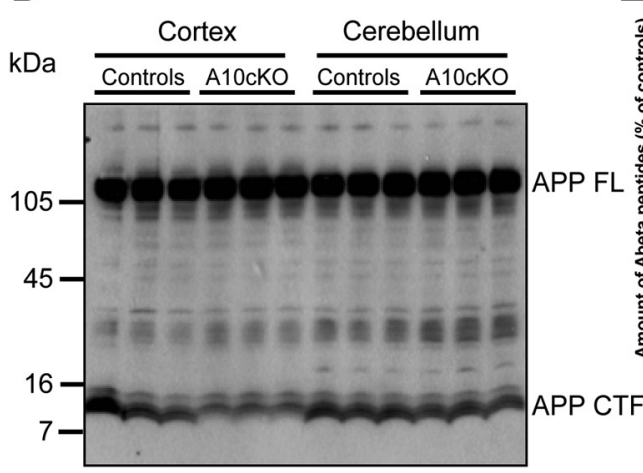

C

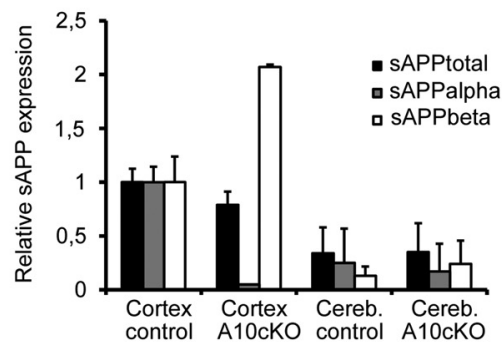

$\mathbf{E}$

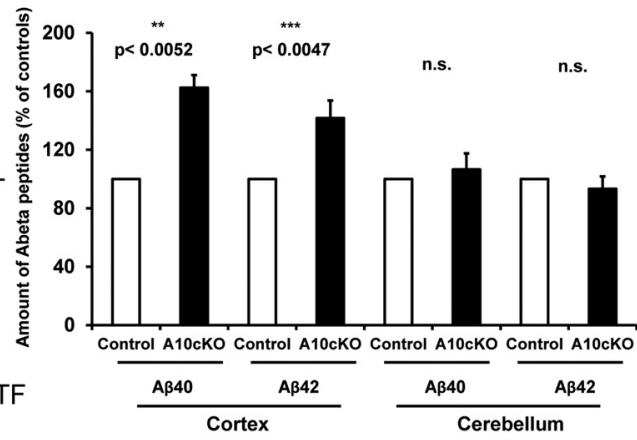

Figure 2. Loss of ADAM10 expression and APP processing in adult A10cK0 mice. A, Western blot analysis of the ADAM10 protein expression in cortex lysates of A10cK0s and littermate controls at different postnatal stages (P5, P10, and P17). Actin served as control for equal protein loading. pADAM10, precursor of ADAM10; mADAM10, mature form of ADAM10; ADAM10-CTF, C-terminal fragment of ADAM10. B, Western blot analysis of total soluble APP (sAPP total), soluble APP $\alpha(\operatorname{sAPP} \alpha)$, and soluble APP $\beta(\operatorname{sAPP} \beta)$ of cortex and cerebellar lysates of A10cK0 s and littermate controls.

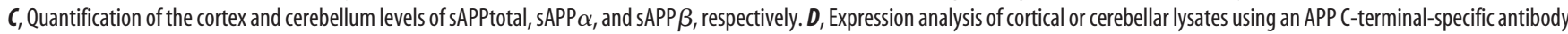
revealing C-terminal stubs and full-length APP, respectively. $\boldsymbol{E}$, ELISA determination of endogenous levels of A $\beta$ species $(1-40$ and $1-42)$ in cortex and cerebellum extracts from controls and A10cK0 mice. Significant differences between the groups are indicated.

animals during the sampling and analysis of learning-relevant information (Otto et al., 1991). As shown in Figure 5C, control mice developed a robust LTP $(1 \min 201 \pm 37 \%$, 60 min $167 \pm$ $37 \%, 120$ min $147 \pm 29 \%$ ), but the same stimulation evoked only a short-term potentiation in A10cKO mice ( 1 min $156 \pm 37 \%, 60$ $\min 86 \pm 7 \%, 120 \min 80 \pm 37 \%, p=0.0384)$. Thus, they completely failed to show LTP as indicated by values that returned to baseline within $7 \mathrm{~min}$ after the first tetanization (Wilcoxon test, $p=0.678$ ).

\section{In vivo hippocampal network activity in $\mathrm{A} 10 \mathrm{cKO}$}

We investigated in vivo hippocampal network activity in urethane-anesthetized adult mice and recorded depth profiles of spontaneous LFPs along the primary somatosensory (S1)
cortex/CA1/dentate gyrus axis (Fig. 6A-D). As A10cKO mutant mice repeatedly died during the surgery while none of the control animals did, the urethane dose was lowered for mutants by $20-25 \%$ eliminating mortality while still maintaining anesthesia depth. Hippocampal LFPs from both control $(n=$ 10 ) and mutant mice $(n=6)$ showed paradoxical (REM) sleep-like activity, i.e., theta/gamma oscillations (Fig. $6 A, B, F)$, and non-REM sleep-like LFP epochs with the characteristic sharp wave/ripple complexes in CA1 (Fig. 6C,D). These activity patterns alternated spontaneously throughout the recording session (Fig. 6E). Analysis of non-REM sleep-like oscillations did not reveal differences in ripple properties (frequency, amplitude, length, number) or sharp wave amplitudes (data not shown). Quantitative LFP analysis of theta power depth profiles 
A

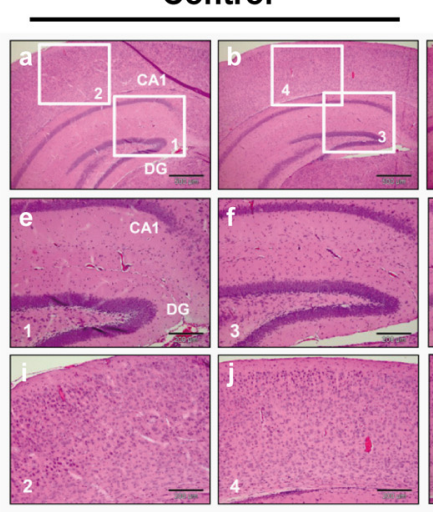

B
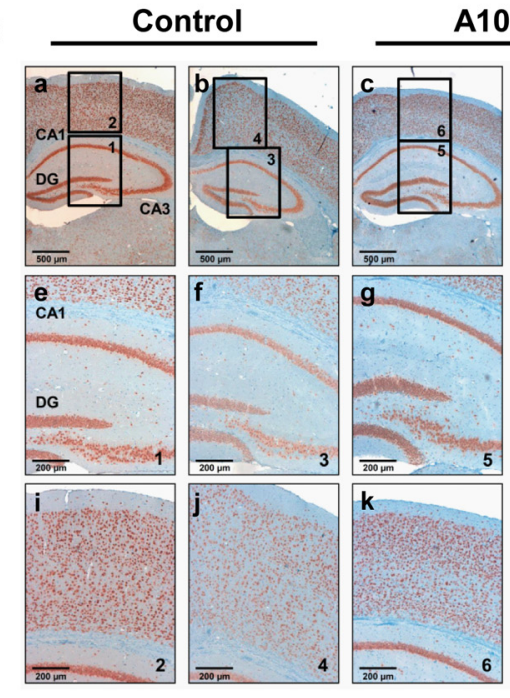

A10cKO

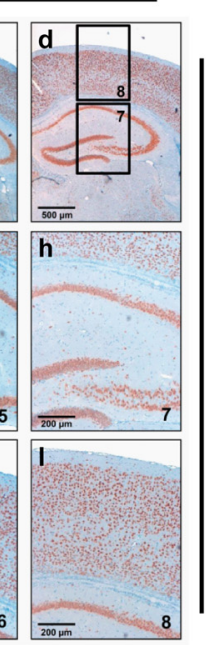

$\underset{\mathbf{z}}{\mathbf{z}}$

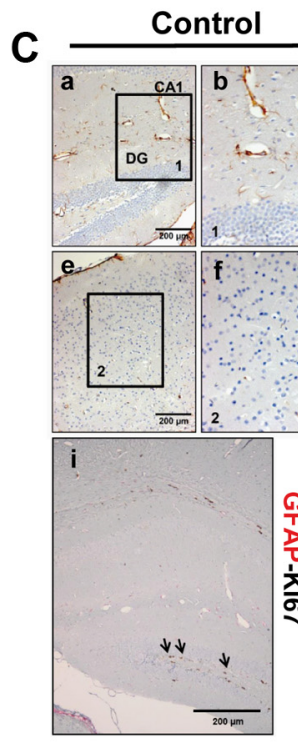

Control
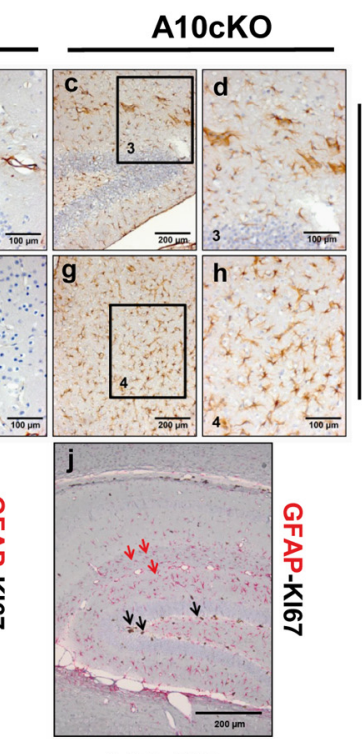

A10cKo
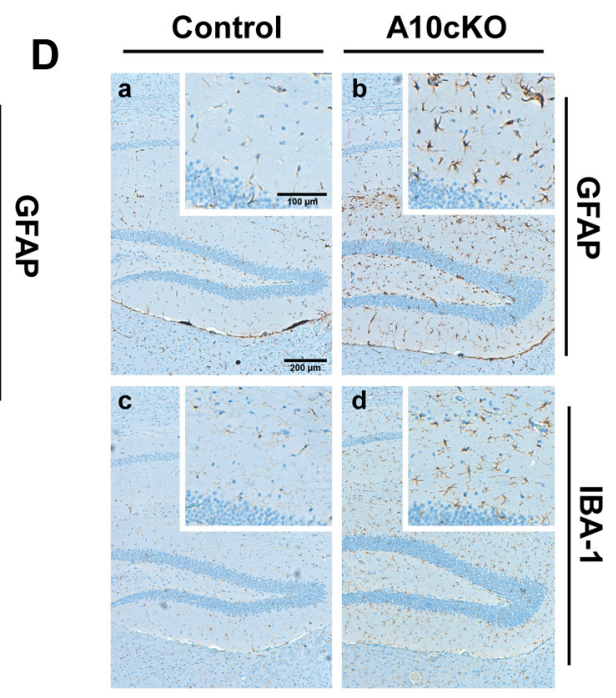

Figure 3. Histological analysis of control and A10cK0 mice at different developmental stages. $A$, H\&E staining of two control and two A10cK0 cortex and hippocampal sections. Magnified images of the boxes indicated on the top are shown in the middle and bottom, respectively. Scale bars: (for $\boldsymbol{a}-\boldsymbol{d}$ ) $500 \mu \mathrm{m}$; (for $\mathbf{e}-\boldsymbol{I}$ ) $200 \mu \mathrm{m}$. B, Neuronal nuclei (NeuN) staining of cortex and hippocampus of two control and two A10cK0 mice. Scale bars: (for $\boldsymbol{a}-\boldsymbol{d}$ ) $500 \mu \mathrm{m}$; (for $\boldsymbol{e}-\boldsymbol{I}$ ) $200 \mu \mathrm{m}$. C, GFAP staining in hippocampal ( $\boldsymbol{(} \boldsymbol{-} \boldsymbol{d}$ ) and cortical (e- $\boldsymbol{h}$ ) section of a control and an A10cK0 (P20) mouse reveals astrogliosis in the mutant brain regions. Double staining with GFAP and Ki67 of control hippocampal section (i) and A10cK0 sections (j) revealed that the increased GFAP immunoreactivity is not due to increased proliferation of astrocytes. Scale bars: (for $\boldsymbol{a}, \boldsymbol{c}, \boldsymbol{e}, \boldsymbol{g}, \boldsymbol{i}, \boldsymbol{j}$ ) $200 \mu \mathrm{m}$; (for $\boldsymbol{b}, \boldsymbol{d}, \boldsymbol{f}, \boldsymbol{h}$ ) $100 \mu \mathrm{m}$. D, Astrogliosis (upper row) and microglia activation (bottom) in 30-week-old control and A10cK0 mice as revealed by immunostaining for GFAP and Iba-1. Scale bars: (for overviews) $200 \mu \mathrm{m}$; (for insets) $100 \mu \mathrm{m}$. 
A

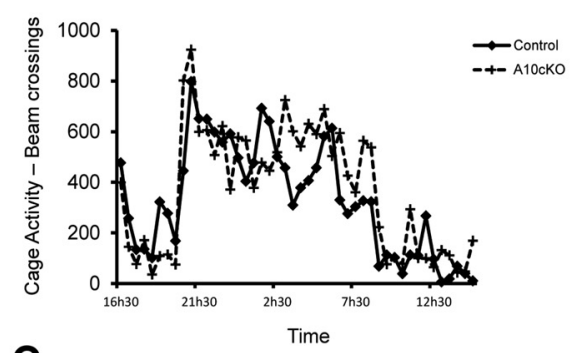

C

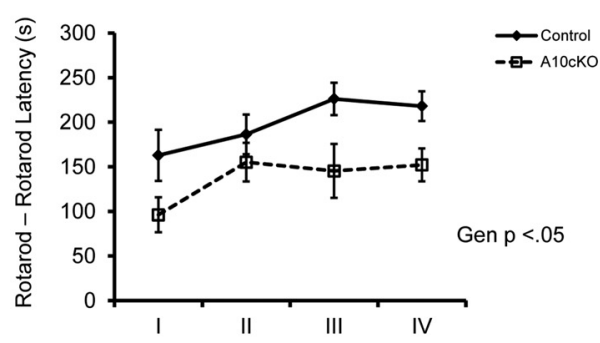

E

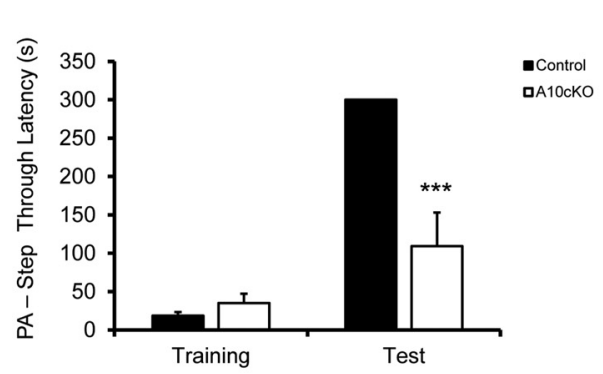

G

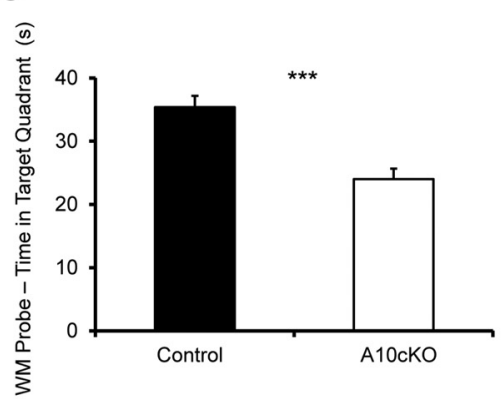

B

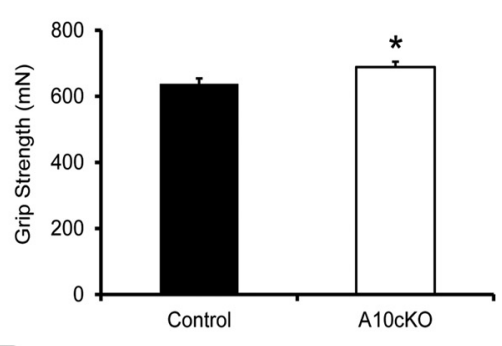

D

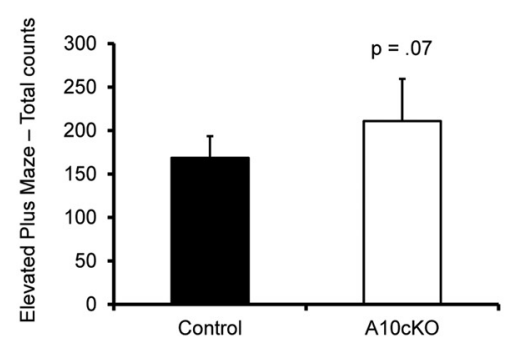

F
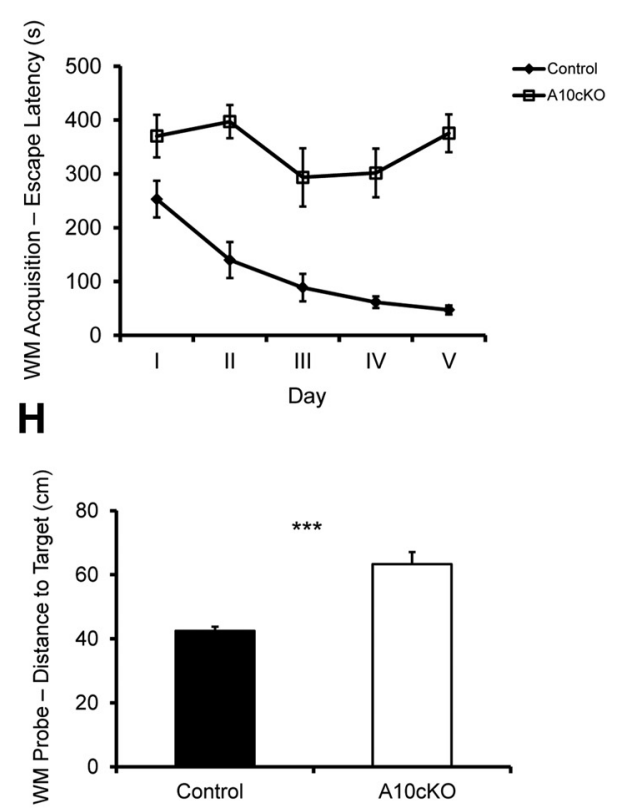

Figure 4. Neuromotor function, exploration behavior, and learning in A10cKO mice. A, Circadian cage activity assay: recording of beam crossings and comparison of control versus A10cK0 mice. $\boldsymbol{B}$, Determination of grip strength. $\boldsymbol{C}$, Rotarod performance and drop latency of control and A10cKO mice. $\boldsymbol{D}$, Elevated plus maze test revealed an increased activity of the A10cKO mice. $\boldsymbol{E}$, Passive avoidance test measured by step through latency (s, seconds) showed impaired performance in A10cKO mice. $\boldsymbol{F}$, Water maze acquisition tests shows the escape latency (s) and revealed an impaired learning of A10cKO mice to find the platform. $\mathbf{G}$, Water maze test: time spent in target quadrant (s). $\boldsymbol{H}$, Water maze test: distance to target (centimeters).

during REM sleep-like network activity revealed reduced power in hippocampus (stratum oriens and stratum lacunosum moleculare) and deep layers of S1 cortex (Fig. $6 F, G$ ). Furthermore, LFP gamma power in the CA1 pyramidal layer during REM sleeplike network activity was lower in mutants than in controls (Fig. $6 \mathrm{H}$ ). In addition, cross-frequency coupling between theta and gamma oscillations, i.e., the modulation of gamma amplitude by theta phase in mutants, was lower in stratum oriens and stratum lacunosum moleculare. Together, the data indicate that ADAM10 deletion in the forebrain impairs REM sleep-like in vivo hippocampal network activity and theta/gamma cross-frequency coupling.

\section{Reduced NMDAR expression and impaired postsynaptic} plasticity in the ADAM10-deleted brain

The electrophysiological abnormalities in the A10cKO mice suggested a defect in postsynaptic function. To correlate this on the molecular level, we first analyzed the expression level of postsynaptic receptor and scaffold molecules. We found that the protein expression of PSD-95 was slightly reduced ( $74 \%$ of control) whereas the levels of the NMDA receptor subunits $2 \mathrm{~A}$ and $2 \mathrm{~B}$ were more strongly (61\% for NMDAR2A and $35 \%$ for NMDAR2B as compared with control expression) reduced in A10cKO cortex lysates (Fig. 7A). mRNA levels of NMDAR subunits were unaffected in $\mathrm{A} 10 \mathrm{cKO}$ cortex preparations compared 
Table 2. Open field test and social exploration assay

\begin{tabular}{lccc}
\hline & Control & A10cK0 & \\
\hline Open field & & & \\
$\quad$ Total path length (cm) & 2857 & 3834 & \\
$\quad$ Center entries & 11.9 & 4.7 & $p=0.09$ \\
$\quad$ Time in center (s) & 43.9 & $6.1^{* *}$ & $p<0.01$ \\
Latency to center entry (s) & 160 & 322 & \\
$\quad$ Corner entries & 34 & 25.8 & \\
$\quad$ \% Path length in center & 9.8 & $2.1^{* *}$ & $p<0.01$ \\
Social exploration & & & \\
Total path length (cm) & 2931 & 3088 & \\
Center entries & 17.9 & $7.8^{*}$ & $p<0.05$ \\
Time in center (s) & 290 & $70^{* *}$ & $p<0.01$ \\
Latency to center entry (s) & 103 & 338 & $p=0.09$ \\
Corner entries & 24 & $46^{*}$ & $p<0.05$ \\
\% Path length in center & 47.7 & $11.6^{* *}$ & $p<0.01$ \\
\hline
\end{tabular}
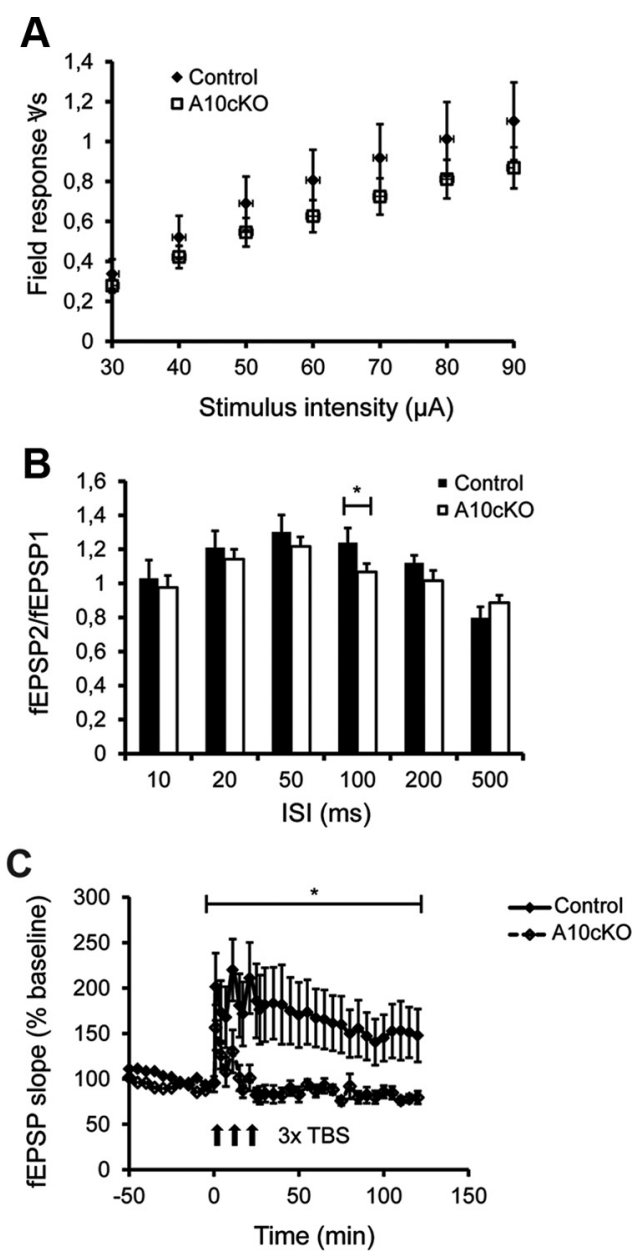

Figure 5. LTP in A10cK0 mice. $A$, ADAM10 deletion had no effect on basal synaptic transmission with values comparable between genotypes. $\boldsymbol{B}$, Paired-pulse ratios, a measure of shortterm plasticity, was not different between genotypes except for the $100 \mathrm{~ms}$ ratio (see Results). C, Strong stimulation consisting of $3 \times$ TBS failed to evoke LTP in A10cKOs but induced robust potentiation in wild-type mice.

with controls (data not shown). The reduced neuronal NMDAR expression was also confirmed by immunohistochemical staining for the NR1-subunit in sections from the hippocampus (Fig. 7B). Silver staining of the apical dendrites of neurons in the stratum radiatum revealed an apparently reduced number and altered shape of synaptic spines in the A10cKO samples (Fig. 7C). Ultrastructural analysis of the synapses and spines from the same brain regions allowed a closer look at their morphology. The investigation of dendritic spines in the stratum radiatum from control and A10cKO hippocampal neurons revealed the altered morphology of spines in mice lacking neuronal ADAM10. Whereas in wildtype animals postsynaptic structures, e.g., spine heads, are usually small and rounded, rarely displaying a neck in ultrathin sections, spines from the ADAM10-deficient mice are stubby and enlarged, contain mitochondria, and are often connected directly to the dendritic shaft without a typical spine neck (Fig. 7D). Despite these abnormalities synapses are regularly formed (Fig. $7 E$ ) with typical asymmetric postsynaptic densities and densely packed vesicles in the presynaptic boutons.

A possible explanation for the stubby spine morphology in ADAM10-depleted neurons is that the contact between presynaptic and postsynaptic structures is determined by a number of well defined surface transmembrane proteins such as cadherins, neurexins, neuroligins (Arikkath and Reichardt, 2008; Bottos et al., 2011), or even APP (Zheng et al., 2011; Tyan et al., 2012). Using our CaMKII $\alpha$-Cre ADAM10-depleted cKO mice we were already able to demonstrate that neuroligin-1 is a substrate for ADAM10 (Suzuki et al., 2012). Looking at the ectodomain shedding of N-Cadherin, which we also previously implicated as an ADAM10 substrate (Reiss et al., 2005), we also realized that the generation of the CTF1 of N-Cadherin as a product of ectodomain shedding was significantly reduced ( $54 \%$ as compared with controls) in A10cKO cortex samples (Fig. $7 F$ ) confirming the postnatal role of ADAM10 for modulation of N-Cadherin surface levels in vivo.

As an additional example for the impact of ADAM10 deficiency on the proteome of the synaptic membrane the shedding of the neuronal cell adhesion molecule Nectin-1 was shown to be inhibited in $\mathrm{A} 10 \mathrm{cKO}$ as revealed by a reduced level of the Nectin1-CTF1 in the ADAM10-deleted cortex extracts (Fig 7G).

Together, our data suggest that ADAM10 controls multiple shedding events in the adult brain, which are essential for the development and maintenance of synaptic plasticity.

\section{Discussion}

The metalloproteinase ADAM10 has raised considerable attention due to its central function in the regulation of classical Notch 1 signaling and in mediating the $\alpha$-secretase processing step of the APP in vivo (Weber and Saftig, 2012). To address the question to what extent ADAM10 contributes to CNS development we previously disrupted the protease in neural progenitor cells using a Nestin-Cre deleter strain (Jorissen et al., 2010). This deletion strategy, starting at embryonic day 9, led to embryonic lethality with intracranial hemorrhages and disrupted organization of the cortical region due to precocious neuronal differentiation resulting in an early depletion of progenitor cells. In ADAM10-deleted neurons derived from these mice both Notch1 signaling and Notch1-dependent cell fate decisions but also APP$\alpha$-secretase cleavage were largely reduced (Jorissen et al., 2010). We hypothesized that the disruption of ADAM10 in postnatal neurons also leads to a developmental phenotype. However, our finding that there is a major role of ADAM10 in the establishment of postsynaptic contacts was unexpected.

The aim of the current study was to circumvent the embryonic lethality of the Nestin-Cre A10cKO since the severe phenotype precluded the analysis of ADAM10 function, substrate processing events, and their potential physiological function in the adult CNS. Postnatal neuronal ADAM10 deletion was achieved after expression of the CaMKII $\alpha$ promoter-driven Cre recombinase (Casanova et al., 2001). Expression analysis for ADAM10 in the 
A

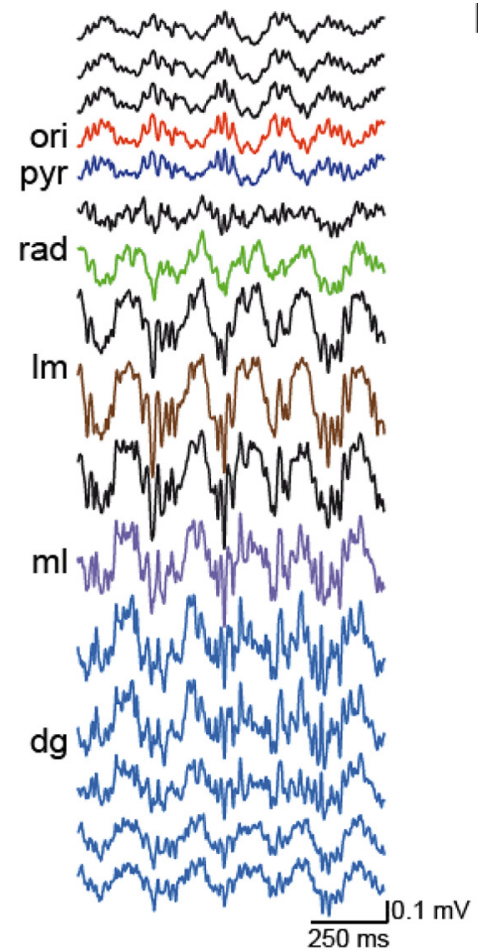

B
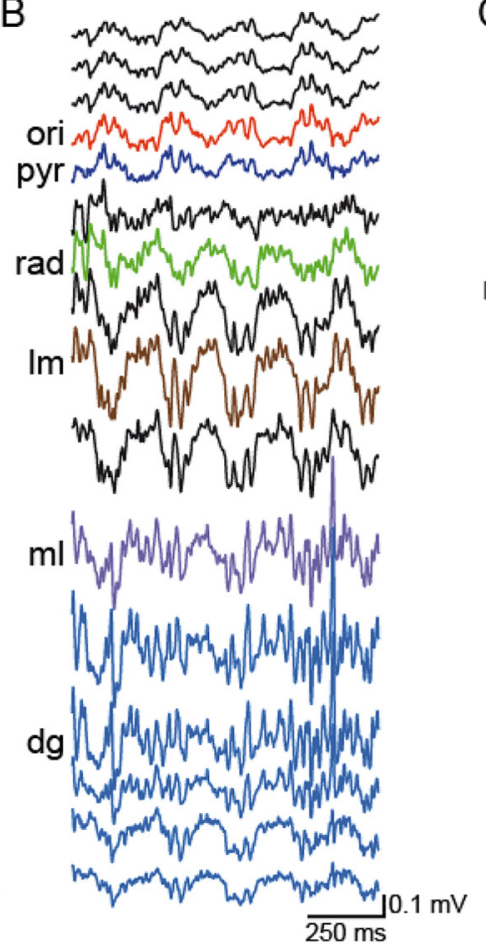

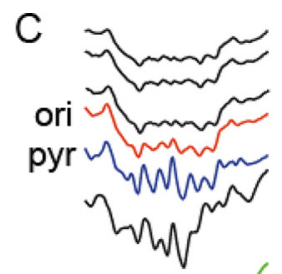

rad
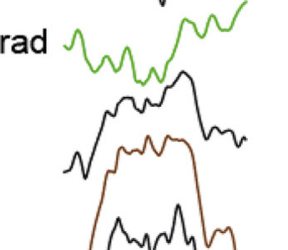

$\mathrm{Im}$

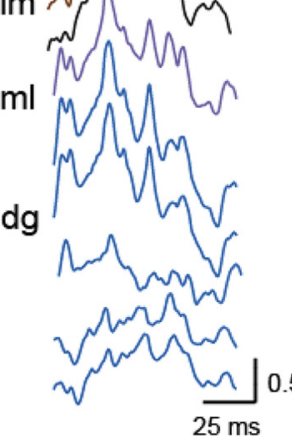

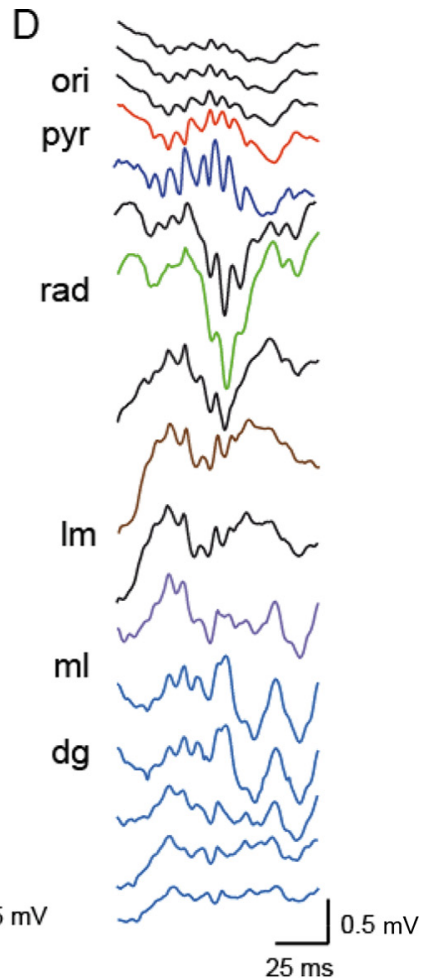
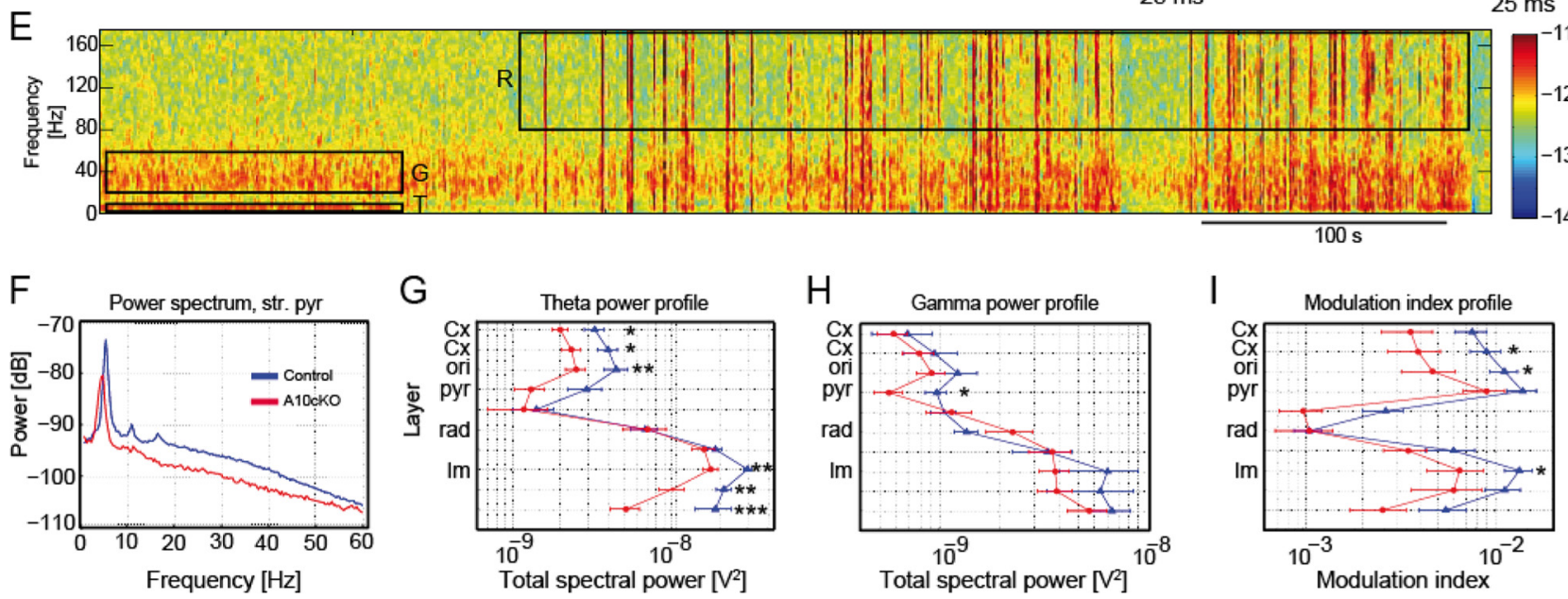

Figure 6. In vivo network activity in the hippocampus of A10cK0 mice. $A-D$, Silicon probe multisite recording of LFP depth profiles along the $S 1$ cortex-CA1- dentate gyrus axis during paradoxical (REM) sleep-like $(\boldsymbol{A}, \boldsymbol{B})$ and SWS-like brain states $(\boldsymbol{C}, \boldsymbol{D})$. Hippocampal layers corresponding to the individual LFP traces are indicated on the left. $\boldsymbol{E}$, Time-frequency spectrogram of the spontaneous LFP recorded from the CA1 pyramidal layer in an urethane-anesthetized mouse shows spontaneous alternation of REM-like and non-REM-like network activity. $F$, LFP power spectrum during a REM sleep-like period from a control and a mutant animal. $\mathbf{G}$, LFP theta power depth profile and $(\boldsymbol{H})$ LFP gamma power depth profile from the layers depicted in $\boldsymbol{A}-\boldsymbol{D}$. $\boldsymbol{I}$, Theta/gamma cross-frequency coupling depth profile. ori, stratum oriens; pyr, stratum pyramidale; rad, stratum radiatum; Im, stratum lacunosum moleculare; $\mathrm{ml}$, molecular layer; $\mathrm{dg}$, dentate gyrus; $\mathrm{T}$, theta frequency range; $\mathrm{G}$, gamma frequency range; $\mathrm{R}$, ripple frequency range; $\mathrm{C}$, cortex; ${ }^{*} p<0.05,{ }^{* *} p<0.01,{ }^{* * *} p<0.001$ Mann-Whitney test.

A10cKO cortex lysates revealed an almost complete loss of sAPP $\alpha$. This not only supports our chosen strategy but also underscores that in adult neurons ADAM10 is the most essential protease for the ectodomain shedding of APP (Jorissen et al., 2010; Kuhn et al., 2010). Interestingly, a parallel upregulation of the $\beta$-secretase-mediated APP processing was observed, which is apparently not due to an increased expression of BACE-1 in the A10cKO brains (data not shown) but most likely a result of more full-length APP substrate available for BACE-1 cleavage after endocytosis of APP from the cell surface (Tan and Evin, 2012). The role of sAPP $\alpha$ has been a matter of debate and it has been linked to neuritogenesis, neuroprotection, growth factor activity, and LTP by increasing synaptic density, memory retention, and metal homeostasis (for review, see Chasseigneaux and Allinquant, 2012). The lack of sAPP $\alpha$ generation in ADAM10-deficient neurons may be directly connected to the observed phenotypic alterations related to memory function and electrophysiological performance in the A10cKO mice. We found that hippocampal theta oscillations and theta/gamma cross-frequency coupling, patterns that are thought to be of importance for hippocampusdependent cognitive tasks (Buzsáki, 2002; Buzsáki and Wang, 2012), were most consistently altered in CA1 stratum lacunosum moleculare, the distal dendrite-containing layer receiving direct entorhinal cortical input via the perforant path. In the context of $\operatorname{sAPP} \alpha$ generation, it is also interesting to note that some aspects 

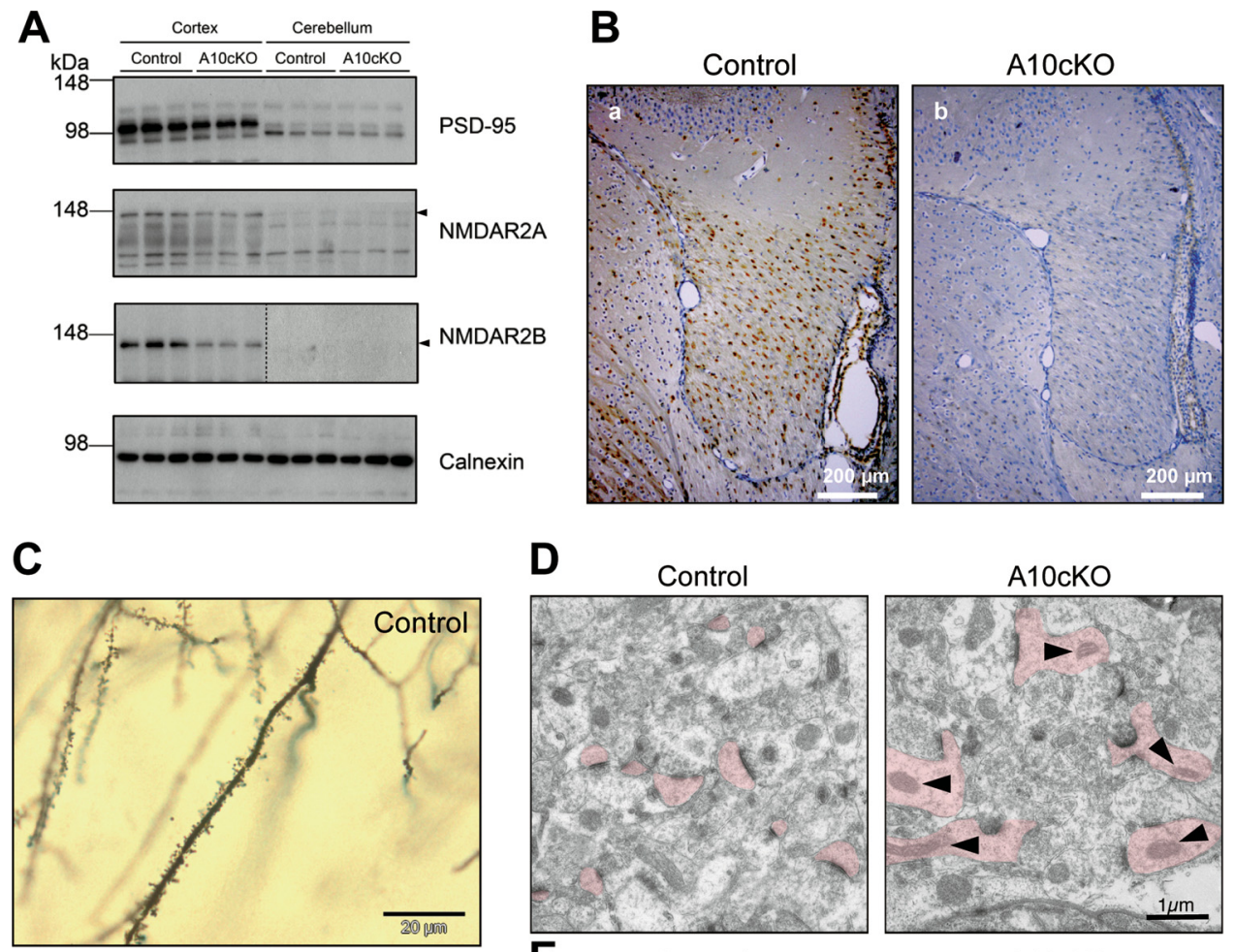

D
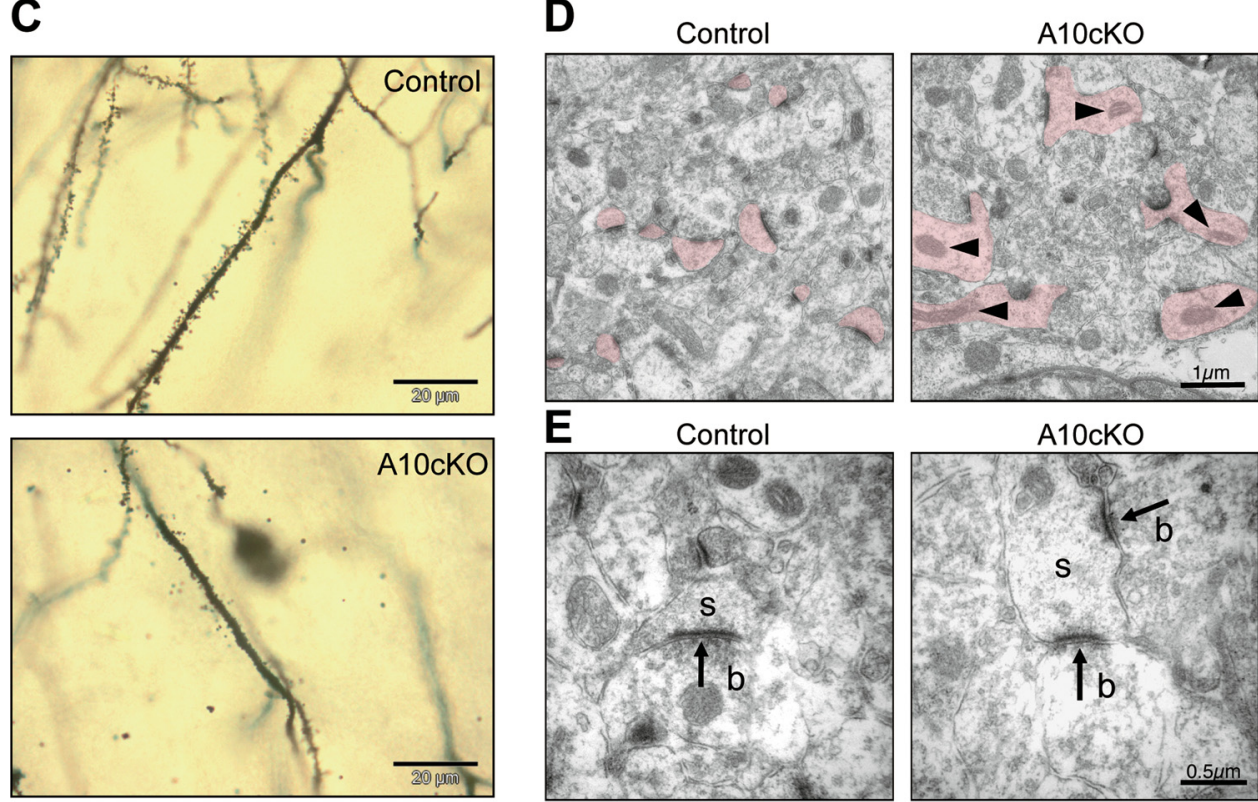

E
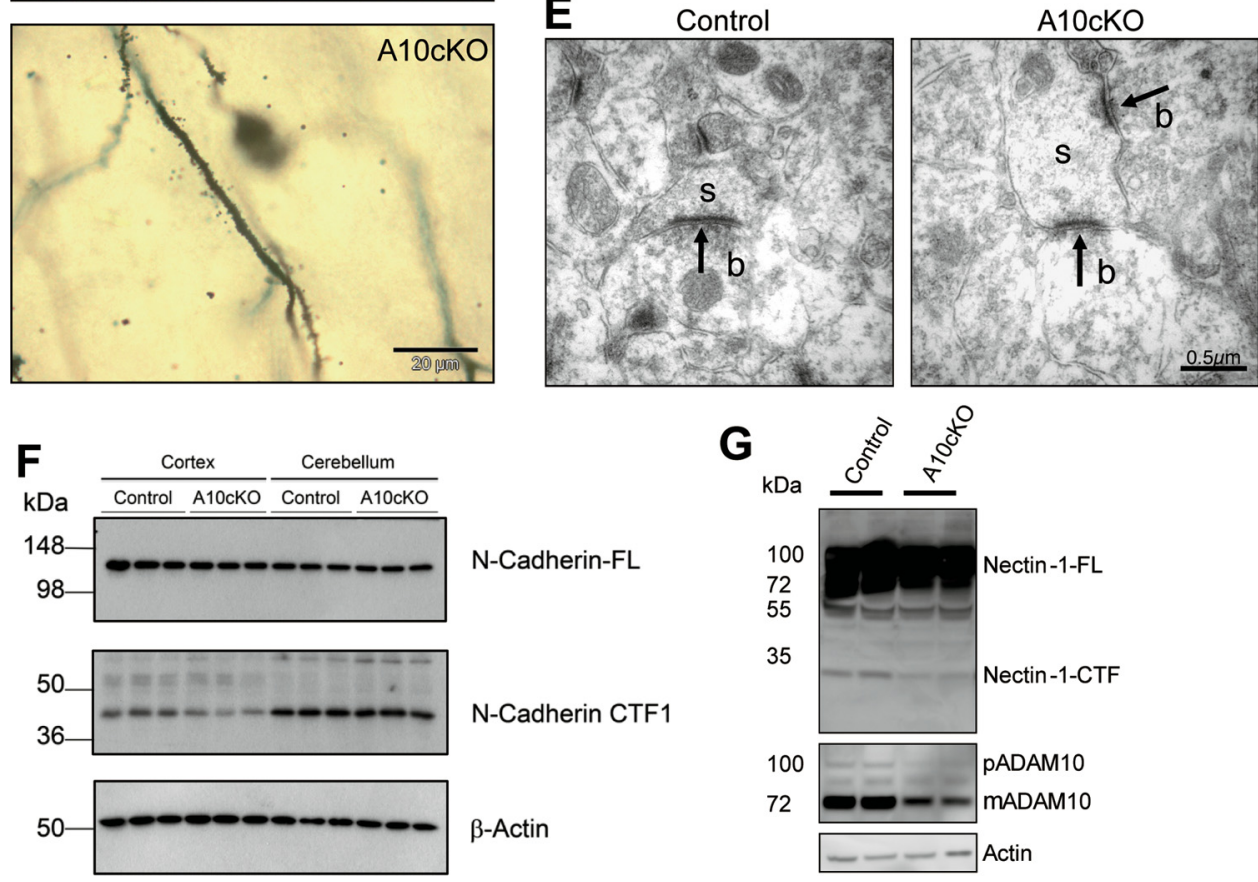

$\mathrm{N}-$ Cadherin-FL

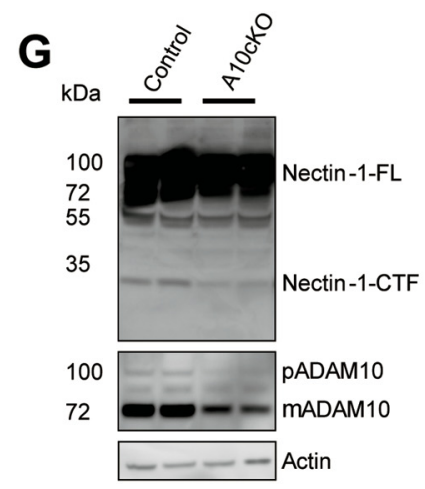

Figure 7. Reduced NMDAR expression, decreased N-Cadherin shedding, and altered spine morphology in A10cK0 mice. A, Analysis of postsynaptic protein expression revealed a decreased expression of the PSD-95 and the NMDAR subunits $2 \mathrm{~A}$ and 2B, respectively. The decreased expression level was obvious in cortical lysates and not observed in nontargeted cerebellar lysate of control and A10cK0 mice. Calnexin staining was used as a loading control. B, NMDAR downregulation could also be visualized in the hippocampus of A10cK0 mice by analyzing the NR1-subunit expression. C, Dendritic segments were imaged after Golgi silver staining. A reduced number and appearance of synaptic spines in A10cK0 mice is obvious. Representative zoomed-in images are shown. Whereas in control mice basal dendritic shafts were densely covered with dendritic spines, in A10cKO mice the dendrites had a reduced number of spines. $D, E$, Electron micrographs of synaptic contacts from control and A10cK0 mice. In the stratum radiatum of A10cK0 mice postsynaptic densities were frequently found to be in connection with dendritic shafts indicating an altered shrunken and stubby-like spine morphology (pink-shaded structures). Note the appearance of mitochondria near the postsynaptic densities (arrowheads). Spines in the wild-type were characterized by their tiny spine heads (pink) without any organelles. Thin spine necks were occasionally found. The overall morphology of synaptic contacts, however, is unaltered. Spines (s) show typical asymmetric postsynaptic densities (arrows) and presynaptic boutons (b) are loaded with many vesicles. $F, \mathrm{~N}$-Cadherin ectodomain shedding (carboxy terminal stub: (TF generation) is reduced in ADAM10deficient cortex samples. G, Nectin-1 CTF generation is also reduced in cortex samples from A10cKO mice.

of the phenotype including epileptic seizures and premature death were also observed in transgenic mice with neuronal overexpression of human APP mutated at the $\alpha$-secretase site (Moechars et al., 1996, Moechars et al., 1998). The memory de- fects of APP knockout mice could be rescued by crossing in $\operatorname{sAPP} \alpha$ knockin mice (Ring et al., 2007). Interestingly and comparable to our findings reported here, old APP knock-out mice and APPdeficient primary neurons show a decrease in spine density and 
number, accompanied by a reduction of LTP expression, which could be partially restored with $\operatorname{sAPP} \alpha$-conditioned medium (Tyan et al., 2012). In this context our findings of increased endogenous levels of $\mathrm{A} \beta$ species in the conditional knock-out cortex samples underline that this may have a direct impact on the spinogenesis and synaptic remodeling. It is therefore likely that the increased level of $\mathrm{A} \beta$ due to the lack of ADAM10 may have impact on spine number and plasticity, possibly in an NMDARdependent manner (Roselli et al., 2005; Wei et al., 2010). This effect may also occur through an $\mathrm{A} \beta_{1-40}$-induced degradation of PSD-95, similar to the reduced expression observed in this study, at glutamatergic synapses (Roselli et al., 2005). As suggested recently the synaptotoxic effects of $\mathrm{A} \beta_{1-42}$ may be caused by an overactivation of the CAMKK2-AMPK kinase pathway inducing dendritic spine loss (Mairet-Coello et al., 2013). The $A \beta$ inhibitory effects on synaptic plasticity may also occur through promotion of NMDAR endocytosis and an associated depression of NMDA-evoked currents (Snyder et al., 2005). Interestingly, under physiological conditions an activation of NMDARs leads to a Wnt/ $\beta$-catenin signaling-dependent upregulation of ADAM10 (Wan et al., 2012). An increase in $A \beta$ levels may also lead to an increased binding to the Ephrin B2 (EphB2) receptor potentially leading to EphB2/NMDAR-complex degradation (Cissé et al., 2011; Nolt et al., 2011).

The phenotype of the classical ADAM10 knock-out (Hartmann et al., 2002) as well as conditional knock-outs for skin, vasculature, and embryonic brain (Jorissen et al., 2010; Glomski et al., 2011; Weber et al., 2011) strongly argued for ADAM10 as the essential protease regulating Notch1dependent developmental processes. A defect in the Notch1signaling pathway may also contribute to the observed synaptic phenotype in A10cKO brains. An inhibition of Notch1 signaling led to a reduction of dendritic spines and branch points (Redmond et al., 2000). Conditional deletion of the Notch receptor or components of the Notch pathway demonstrated that Notch1 signaling contributes to survival and dendritic morphology of newly born granule cells (Breunig et al., 2007). Null mutations in Notch 1 on one allele or the downstream cofactor RBP-J were also described to be associated with deficits in spatial learning and memory (Costa et al., 2003). The contribution of Notch1 signaling to our observed phenotype is rather minor since apart from a reduction of Hes 5 transcription level we did not observe an altered expression of other Notch1-dependent genes (data not shown). Interestingly, conditional knock-out mice lacking both presenilins (Saura et al., 2004) or the $\gamma$-secretase cofactor nicastrin (Tabuchi et al., 2009) in the postnatal forebrain also showed an impaired hippocampal memory, defects in synaptic plasticity, and lower NMDAR levels. It may well be that the
NMDAR effects of the presenilin mutations on synaptic transmission are exerted by presynaptic deficits due to transsynaptic mechanisms (Zhang et al., 2010).

In contrast to presenilins, ADAM10 as a sheddase not only affects signaling events in cis but also in trans by liberating soluble ectodomains. Dendritic spines in the CNS are essential components of synaptic functions that control learning and memory. Depending on synaptic activity, developmental age, and brain region, molecular events at the dendritic spines lead to morphological changes thereby regulating synaptic plasticity (Bourne and Harris, 2011). The removal, establishment, and stabilization of dendritic spines and the maintenance of synaptic structures is largely controlled by synaptic adhesion molecules such as cadherins, protocadherins, neural cell adhesion molecule, L1-family cell adhesion molecules, neurexins, and neuroligins (Dalva et al., 2007; Siddiqui and Craig, 2011). We could previously show that a number of these proteins are subject to ADAM10-mediated ectodomain shedding (Maretzky et al., 2005; Reiss et al., 2005, 2006; Kim et al., 2010; Suzuki et al., 2012). In agreement with our findings, the generation of the shedding product of $\mathrm{N}$-Cadherin processing is reduced in cortical lysates of $\mathrm{A} 10 \mathrm{cKO}$ mice. N-Cadherin shedding by ADAM10 also controls cell-cell adhesion and synaptic plasticity (Malinverno et al., 2010). Altering synaptic localization of ADAM10 led to an increase in size of spines comparable to the stubby spine morphology observed in the A10cKO mice. Nectin-1 as a $\mathrm{Ca}^{2+}$-independent cell adhesion molecule together with its adaptor protein afadin colocalizes with components of the cadherin/catenin system in postsynaptic structures of 
the hippocampus (Mizoguchi et al., 2002) and regulates spine shape and structure (Togashi et al., 2006). Using P1 brain homogenates of Nestin-Cre-deleted ADAM10 mice, a reduced shedding of Nectin-1 was found (Kim et al., 2010) possibly also explaining part of the spine phenotype in the CaMKII $\alpha$-Cre A10cKO mice. Also in the adult neurons analyzed in this study Nectin-1 shedding was dependent on the presence of ADAM10. Interestingly, in primary hippocampal neurons the expression of Nectin-1 mutants, which are refractory to ectodomain shedding, suggested that ectodomain shedding of Nectin-1 is required for the formation of synapses and for the regulation of the density of dendritic spines (Lim et al., 2012). Adding to the complex role of ADAM10 in controlling the shedding of postsynaptic cell adhesion molecules, very recent studies using ADAM10 knock-out fibroblasts but also analyzing brain microsome fractions from the A10cKO mice described here revealed that the major sheddase of the potent synaptogenic protein neuroligin-1 (NL1) in brain is ADAM10. The shedding of NL1, which can be triggered by synaptic activity or binding to neurexins, leads to an elimination of NL1 at the postsynaptic cell surface and a decreased synaptogenic activity (Suzuki et al., 2012). The essential role of NL1 in the control of synapse formation and number (Kwon et al., 2012) may therefore be tightly linked to the activity of the sheddase ADAM10. It also cannot be excluded that the previously described ADAM10 shedding of additional central molecules of the CNS, like the ephrins and their receptors (Hattori et al., 2000; Janes et al., 2005), the prion protein (Vincent et al., 2001; Altmeppen et al., 2011), and axon guidance molecules such as neuronal adhesion molecule (Hinkle et al., 2006) and L1 adhesion molecule (Gutwein et al., 2003), contribute to the phenotype of the mutant mice. The A10cKO mice are also an excellent tool to study the protein composition of the postsynaptic membrane in the presence and absence of ADAM10 thereby providing a more complete overview about the sheddome of ADAM10 at these cellular sites revealing the importance of ADAM10 for postsynaptic functions. On the other hand, it highlights the hitherto poorly recognized role of ectodomain shedding in general for synaptogenesis and the specific role of ADAM10 in this process (Fig. 8). It also may raise the question of whether ADAM10 may be used as a therapeutic target for the treatment of AD. Overexpression of ADAM10 in transgenic mouse models (Postina et al., 2004; Fahrenholz and Postina, 2006) has been surprisingly well tolerated suggesting that a suitable therapeutic window may exist that allows a beneficial modulation of the activity of this protease in postmitotic cells, such as neurons.

In conclusion, we present the first in vivo characterization of the consequences of postnatal neuron-specific loss of ADAM10. Our study revealed that ADAM10 mediates the shedding of a number of neuronal substrates including APP, Notch1, N-Cadherin, Nectin-1 and postsynaptic cell adhesion molecules. This represents a central process for the formation and maintenance of synaptic plasticity and function of the adult murine CNS.

\section{References}

Altmeppen HC, Prox J, Puig B, Kluth MA, Bernreuther C, Thurm D, Jorissen E, Petrowitz B, Bartsch U, De Strooper, B, Saftig P, Glatzel M. (2011) Lack of a-disintegrin-and-metalloproteinase ADAM10 leads to intracellular accumulation and loss of shedding of the cellular prion protein in vivo. Mol Neurodegener 6:36. CrossRef Medline

Arikkath J, Reichardt LF (2008) Cadherins and catenins at synapses: roles in synaptogenesis and synaptic plasticity. Trends Neurosci 31:487-494. CrossRef Medline

Balschun D, Moechars D, Callaerts-Vegh Z, Vermaercke B, Van Acker N, Andries L, D'Hooge R (2010) Vesicular glutamate transporter VGLUT1 has a role in hippocampal long-term potentiation and spatial reversal learning. Cereb Cortex 20:684-693. CrossRef Medline

Bottos A, Rissone A, Bussolino F, Arese M (2011) Neurexins and neuroligins: syn- apses look out of the nervous system. Cell Mol Life Sci 68:2655-2666. CrossRef Medline

Bourne JN, Harris KM (2011) Coordination of size and number of excitatory and inhibitory synapses results in a balanced structural plasticity along mature hippocampal CA1 dendrites during LTP. Hippocampus 21:354-373. CrossRef Medline

Breunig JJ, Silbereis J, Vaccarino FM, Sestan N, Rakic P (2007) Notch regulates cell fate and dendrite morphology of newborn neurons in the postnatal dentate gyrus. Proc Natl Acad Sci U S A 104:20558-20563. CrossRef Medline

Buzsáki G (2002) Theta oscillations in the hippocampus. Neuron 33: 325-340. CrossRef Medline

Buzsáki G, Wang XJ (2012) Mechanisms of gamma oscillations. Annu Rev Neurosci 35:203-225. CrossRef Medline

Buzsáki G, Buhl DL, Harris KD, Csicsvari J, Czéh B, Morozov A (2003) Hippocampal network patterns of activity in the mouse. Neuroscience 116:201-211. CrossRef Medline

Casanova E, Fehsenfeld S, Mantamadiotis T, Lemberger T, Greiner E, Stewart AF, Schütz G (2001) A CamKIIalpha iCre BAC allows brain-specific gene inactivation. Genesis 31:37-42. CrossRef Medline

Chasseigneaux S, Allinquant B (2012) Functions of A $\beta, \operatorname{sAPP} \alpha$ and $\operatorname{sAPP} \beta$ : similarities and differences. J Neurochem 120 [Suppl 1]:99-108. CrossRef Medline

Chen YT, Collins LL, Uno H, Chang C (2005) Deficits in motor coordination with aberrant cerebellar development in mice lacking testicular orphan nuclear receptor 4. Mol Cell Biol 25:2722-2732. CrossRef Medline

Cissé M, Halabisky B, Harris J, Devidze N, Dubal DB, Sun B, Orr A, Lotz G, Kim DH, Hamto P, Ho K, Yu GQ, Mucke L (2011) Reversing EphB2 depletion rescues cognitive functions in Alzheimer model. Nature 469:47-52. CrossRef Medline

Costa RM, Honjo T, Silva AJ (2003) Learning and memory deficits in Notch mutant mice. Curr Biol 13:1348-1354. CrossRef Medline

Dalva MB, McClelland AC, Kayser MS (2007) Cell adhesion molecules: signalling functions at the synapse. Nat Rev Neurosci 8:206-220. CrossRef Medline

Endres K, Fahrenholz F (2010) Upregulation of the alpha-secretase ADAM10-risk or reason for hope? FEBS J 277:1585-1596. CrossRef Medline

Epis R, Marcello E, Gardoni F, Vastagh C, Malinverno M, Balducci C, Colombo A, Borroni B, Vara H, Dell'Agli M, Cattabeni F, Giustetto M, Borsello T, Forloni G, Padovani A, Di Luca M (2010) Blocking ADAM10 synaptic trafficking generates a model of sporadic Alzheimer's disease. Brain 133:3323-3335. CrossRef Medline

Fahrenholz F, Postina R (2006) Alpha-secretase activation-an approach to Alzheimer's disease therapy. Neurodegener Dis 3:255-261. CrossRef Medline

Glomski K, Monette S, Manova K, De Strooper B, Saftig P, Blobel CP (2011) Deletion of Adam10 in endothelial cells leads to defects in organ-specific vascular structures. Blood 118:1163-1174. CrossRef Medline

Gutwein P, Mechtersheimer S, Riedle S, Stoeck A, Gast D, Joumaa S, Zentgraf H, Fogel M, Altevogt DP (2003) ADAM10-mediated cleavage of L1 adhesion molecule at the cell surface and in released membrane vesicles. FASEB J 17:292-294. Medline

Hartmann D, de Strooper B, Serneels L, Craessaerts K, Herreman A, Annaert W, Umans L, Lübke T, Lena Illert A, von Figura K, Saftig, P (2002) The disintegrin/ metalloprotease ADAM 10 is essential for Notch signalling but not for alphasecretase activity in fibroblasts. Hum Mol Genet 11:2615-2624. CrossRef Medline

Hattori M, Osterfield M, Flanagan JG (2000a) Regulated cleavage of a contact-mediated axon repellent. Science 289:1360-1365. CrossRef Medline

Hazan L, Zugaro M, Buzsáki G (2006) Klusters, NeuroScope, NDManager: a free software suite for neurophysiological data processing and visualization. J Neurosci Methods 155:207-216. CrossRef Medline

Hinkle CL, Diestel S, Lieberman J, Maness PF (2006) Metalloproteaseinduced ectodomain shedding of neural cell adhesion molecule (NCAM). J Neurobiol 66:1378-1395. CrossRef Medline

Janes PW, Saha N, Barton WA, Kolev MV, Wimmer-Kleikamp SH, Nievergall E, Blobel CP, Himanen JP, Lackmann M, Nikolov DB (2005) Adam meets Eph: an ADAM substrate recognition module acts as a molecular switch for ephrin cleavage in trans. Cell 123:291-304. CrossRef Medline Jorissen E, Prox J, Bernreuther C, Weber S, Schwanbeck R, Serneels L, Snel- 
linx A, Craessaerts K, Thathiah A, Tesseur I, Bartsch U, Weskamp G, Blobel CP, Glatzel M, De Strooper B, Saftig P (2010) The disintegrin/ metalloproteinase ADAM10 is essential for the establishment of the brain cortex. J Neurosci 30:4833-4844. CrossRef Medline

Kim J, Lilliehook C, Dudak A, Prox J, Saftig P, Federoff HJ, Lim ST (2010) Activity-dependent alpha-cleavage of nectin-1 is mediated by a disintegrin and metalloprotease 10 (ADAM10). J Biol Chem 285:22919-22926. CrossRef Medline

Komatsu M, Waguri S, Chiba T, Murata S, Iwata J, Tanida I, Ueno T, Koike M, Uchiyama Y, Kominami E, Tanaka, K (2006) Loss of autophagy in the central nervous system causes neurodegeneration in mice. Nature 441:880-884. CrossRef Medline

Kuhn PH, Wang H, Dislich B, Colombo A, Zeitschel U, Ellwart JW, Kremmer E, Rossner S, Lichtenthaler SF (2010) ADAM10 is the physiologically relevant, constitutive alpha-secretase of the amyloid precursor protein in primary neurons. EMBO J 29:3020-3032. CrossRef Medline

Kwon HB, Kozorovitskiy Y, Oh WJ, Peixoto RT, Akhtar N, Saulnier JL, Gu C, Sabatini BL (2012) Neuroligin-1-dependent competition regulates cortical synaptogenesis and synapse number. Nat Neurosci 15:1667-1674. CrossRef Medline

Lammich S, Kojro E, Postina R, Gilbert S, Pfeiffer R, Jasionowski M, Haass C, Fahrenholz F (1999) Constitutive and regulated alpha-secretase cleavage of Alzheimer's amyloid precursor protein by a disintegrin metalloprotease. Proc Natl Acad Sci U S A 96:3922-3927. CrossRef Medline

Larson J, Lynch G (1986) Induction of synaptic potentiation in hippocampus by patterned stimulation involves two events. Science 232:985-988. CrossRef Medline

Lim ST, Chang A, Giuliano RE, Federoff HJ (2012) Ectodomain shedding of nectin-1 regulates the maintenance of dendritic spine density. J Neurochem 120:741-751. CrossRef Medline

Liou YC, Sun A, Ryo A, Zhou XZ, Yu ZX, Huang HK, Uchida T, Bronson R, Bing G, Li X, Hunter T, Lu KP (2003) Role of the prolyl isomerase Pin1 in protecting against age-dependent neurodegeneration. Nature 424:556-561. CrossRef Medline

Mairet-Coello G, Courchet J, Pieraut S, Courchet V, Maximov A, Polleux F (2013) The CAMKK2-AMPK kinase pathway mediates the synaptotoxic effects of Abeta oligomers through tau phosphorylation. Neuron 78:94-108. CrossRef Medline

Malinverno M, Carta M, Epis R, Marcello E, Verpelli C, Cattabeni F, Sala C, Mulle C, Di Luca M, Gardoni F (2010) 'Synaptic localization and activity of ADAM10 regulate excitatory synapses through $\mathrm{N}$-cadherin cleavage. J Neurosci 30:16343-16355. CrossRef Medline

Marcello E, Gardoni F, Mauceri D, Romorini S, Jeromin A, Epis R, Borroni B, Cattabeni F, Sala C, Padovani A, Di Luca M (2007) Synapse-associated protein-97 mediates alpha-secretase ADAM10 trafficking and promotes its activity. J Neurosci 27:1682-1691. CrossRef Medline

Maretzky T, Schulte M, Ludwig A, Rose-John S, Blobel C, Hartmann D, Altevogt P, Saftig P, Reiss K (2005) L1 is sequentially processed by two differently activated metalloproteases and presenilin/gamma-secretase and regulates neural cell adhesion, cell migration, and neurite outgrowth. Mol Cell Biol 25:9040-9053. CrossRef Medline

Mizoguchi A, Nakanishi H, Kimura K, Matsubara K, Ozaki-Kuroda K, Katata T, Honda T, Kiyohara Y, Heo K, Higashi M, Tsutsumi T, Sonoda S, Ide C, Takai Y (2002) Nectin: an adhesion molecule involved in formation of synapses. J Cell Biol 156:555-565. CrossRef Medline

Moechars D, Lorent K, De Strooper B, Dewachter I, Van Leuven F (1996) Expression in brain of amyloid precursor protein mutated in the alphasecretase site causes disturbed behavior, neuronal degeneration and premature death in transgenic mice. EMBO J 15:1265-1274. Medline

Moechars D, Lorent K, Dewachter I, Baekelandt V, De Strooper B, Van Leuven $F$ (1998) Transgenic mice expressing an alpha-secretion mutant of the amyloid precursor protein in the brain develop a progressive CNS disorder. Behav Brain Res 95:55-64. CrossRef Medline

Nolt MJ, Lin Y, Hruska M, Murphy J, Sheffler-Colins SI, Kayser MS, Passer J, Bennett MV, Zukin RS, Dalva MB (2011) EphB controls NMDA receptor function and synaptic targeting in a subunit-specific manner. J Neurosci 31:5353-5364. CrossRef Medline

Otto T, Eichenbaum H, Wiener SI, Wible CG (1991) Learning-related patterns of CA1 spike trains parallel stimulation parameters optimal for inducing hippocampal long-term potentiation. Hippocampus 1:181-192. CrossRef Medline

Postina R, Schroeder A, Dewachter I, Bohl J, Schmitt U, Kojro E, Prinzen C,
Endres K, Hiemke C, Blessing M, Flamez P, Dequenne A, Godaux E, van Leuven F, Fahrenholz F (2004) A disintegrin-metalloproteinase prevents amyloid plaque formation and hippocampal defects in an Alzheimer disease mouse model. J Clin Invest 113:1456-1464. CrossRef Medline

Raucci A, Cugusi S, Antonelli A, Barabino SM, Monti L, Bierhaus A, Reiss K, Saftig P, Bianchi ME (2008) A soluble form of the receptor for advanced glycation endproducts (RAGE) is produced by proteolytic cleavage of the membrane-bound form by the sheddase a disintegrin and metalloprotease 10 (ADAM10). FASEB J 22:3716-3727. CrossRef Medline

Redmond L, Oh SR, Hicks C, Weinmaster G, Ghosh A (2000) Nuclear Notch1 signaling and the regulation of dendritic development. Nat Neurosci 3:30-40. CrossRef Medline

Reiss K, Saftig P (2009) The "a disintegrin and metalloprotease" (ADAM) family of sheddases: physiological and cellular functions. Semin Cell Dev Biol 20:126-137. CrossRef Medline

Reiss K, Maretzky T, Ludwig A, Tousseyn T, de Strooper B, Hartmann D, Saftig P (2005) ADAM10 cleavage of N-cadherin and regulation of cellcell adhesion and beta-catenin nuclear signalling. EMBO J 24:742-752. CrossRef Medline

Reiss K, Maretzky T, Haas IG, Schulte M, Ludwig A, Frank M, Saftig P (2006) Regulated ADAM10-dependent ectodomain shedding of gamma-protocadherin C3 modulates cell-cell adhesion. J Biol Chem 281:21735-21744. CrossRef Medline

Ring S, Weyer SW, Kilian SB, Waldron E, Pietrzik CU, Filippov MA, Herms J, Buchholz C, Eckman CB, Korte M, Wolfer DP, Müller UC (2007) The secreted beta-amyloid precursor protein ectodomain APPs alpha is sufficient to rescue the anatomical, behavioral, and electrophysiological abnormalities of APP-deficient mice. J Neurosci 27:7817-7826. CrossRef Medline

Roselli F, Tirard M, Lu J, Hutzler P, Lamberti P, Livrea P, Morabito M, Almeida OF (2005) Soluble beta-amyloid1-40 induces NMDA-dependent degradation of postsynaptic density-95 at glutamatergic synapses. J Neurosci 25 : 11061-11070. CrossRef Medline

Saura CA, Choi SY, Beglopoulos V, Malkani S, Zhang D, Shankaranarayana Rao BS, Chattarji S, Kelleher RJ 3rd, Kandel ER, Duff K, Kirkwood A, Shen J (2004) Loss of presenilin function causes impairments of memory and synaptic plasticity followed by age-dependent neurodegeneration. Neuron 42:23-36. CrossRef Medline

Siddiqui TJ, Craig AM (2011) Synaptic organizing complexes. Curr Opin Neurobiol 21:132-143. CrossRef Medline

Snyder EM, Nong Y, Almeida CG, Paul S, Moran T, Choi EY, Nairn AC, Salter MW, Lombroso PJ, Gouras GK, Greengard P (2005) Regulation of NMDA receptor trafficking by amyloid-beta. Nat Neurosci 8:1051-1058. CrossRef Medline

Suzuki K, Hayashi Y, Nakahara S, Kumazaki H, Prox J, Horiuchi K, Zeng M, Tanimura S, Nishiyama Y, Osawa S, Sehara-Fujisawa A, Saftig P, Yokoshima S, Fukuyama T, Matsuki N, Koyama R, Tomita T, Iwatsubo T (2012) Activitydependent proteolytic cleavage of neuroligin-1. Neuron 76:410-422. CrossRef Medline

Tabuchi K, Chen G, Südhof TC, Shen J (2009) Conditional forebrain inactivation of nicastrin causes progressive memory impairment and agerelated neurodegeneration. J Neurosci 29:7290-7301. CrossRef Medline

Tan J, Evin G (2012) Beta-site APP-cleaving enzyme 1 trafficking and Alzheimer's disease pathogenesis. J Neurochem 120:869-880. CrossRef Medline

Togashi H, Miyoshi J, Honda T, Sakisaka T, Takai Y, Takeichi M (2006) Interneurite affinity is regulated by heterophilic nectin interactions in concert with the cadherin machinery. J Cell Biol 174:141-151. CrossRef Medline

Tort AB, Komorowski RW, Manns JR, Kopell NJ, Eichenbaum H (2009) Theta-gamma coupling increases during the learning of item-context associations. Proc Natl Acad Sci U S A 106:20942-20947. CrossRef Medline

Tousseyn T, Thathiah A, Jorissen E, Raemaekers T, Konietzko U, Reiss K, Maes E, Snellinx A, Serneels L, Nyabi O, Annaert W, Saftig P, Hartmann D, De Strooper B (2009) ADAM10, the rate-limiting protease of regulated intramembrane proteolysis of Notch and other proteins, is processed by ADAMS-9, ADAMS-15, and the gamma-secretase. J Biol Chem 284:11738-11747. Medline

Tyan SH, Shih AY, Walsh JJ, Maruyama H, Sarsoza F, Ku L, Eggert S, Hof PR, Koo EH, Dickstein DL (2012) Amyloid precursor protein (APP) regulates synaptic structure and function. Mol Cell Neurosci 51:43-52. CrossRef Medline 
Vincent B, Paitel E, Saftig P, Frobert Y, Hartmann D, De Strooper B, Grassi J, Lopez-Perez E, Checler F (2001) The disintegrins ADAM10 and TACE contribute to the constitutive and phorbol ester-regulated normal cleavage of the cellular prion protein. J Biol Chem 276:37743-37746. Medline

Wan XZ, Li B, Li YC, Yang XL, Zhang W, Zhong L, Tang SJ (2012) Activation of NMDA receptors upregulates a disintegrin and metalloproteinase 10 via a Wnt/MAPK signaling pathway. J Neurosci 32:3910-3916. CrossRef Medline

Weber S, Saftig P (2012) Ectodomain shedding and ADAMs in development. Development 139:3693-3709. CrossRef Medline

Weber S, Niessen MT, Prox J, Lüllmann-Rauch R, Schmitz A, Schwanbeck R, Blobel CP, Jorissen E, de Strooper B, Niessen CM, Saftig P (2011) The disintegrin/metalloproteinase Adam 10 is essential for epidermal integrity and Notch-mediated signaling. Development 138:495-505. CrossRef Medline
Wei W, Nguyen LN, Kessels HW, Hagiwara H, Sisodia S, Malinow R (2010) Amyloid beta from axons and dendrites reduces local spine number and plasticity. Nat Neurosci 13:190-196. CrossRef Medline

Zhang D, Zhang C, Ho A, Kirkwood A, Südhof TC, Shen J (2010) Inactivation of presenilins causes pre-synaptic impairment prior to post-synaptic dysfunction. J Neurochem 115:1215-1221. CrossRef Medline

Zheng CY, Seabold GK, Horak M, Petralia RS (2011) MAGUKs, synaptic development, and synaptic plasticity. Neuroscientist 17:493-512. CrossRef Medline

Zhou L, Brouwers N, Benilova I, Vandersteen A, Mercken M, Van Laere K, Van Damme P, Demedts D, Van Leuven F, Sleegers K, Broersen K, Van Broeckhoven C, Vandenberghe R, De Strooper B (2011) Amyloid precursor protein mutation E682K at the alternative beta-secretase cleavage beta'-site increases Abeta generation. EMBO Mol Med 3:291-302. CrossRef Medline 